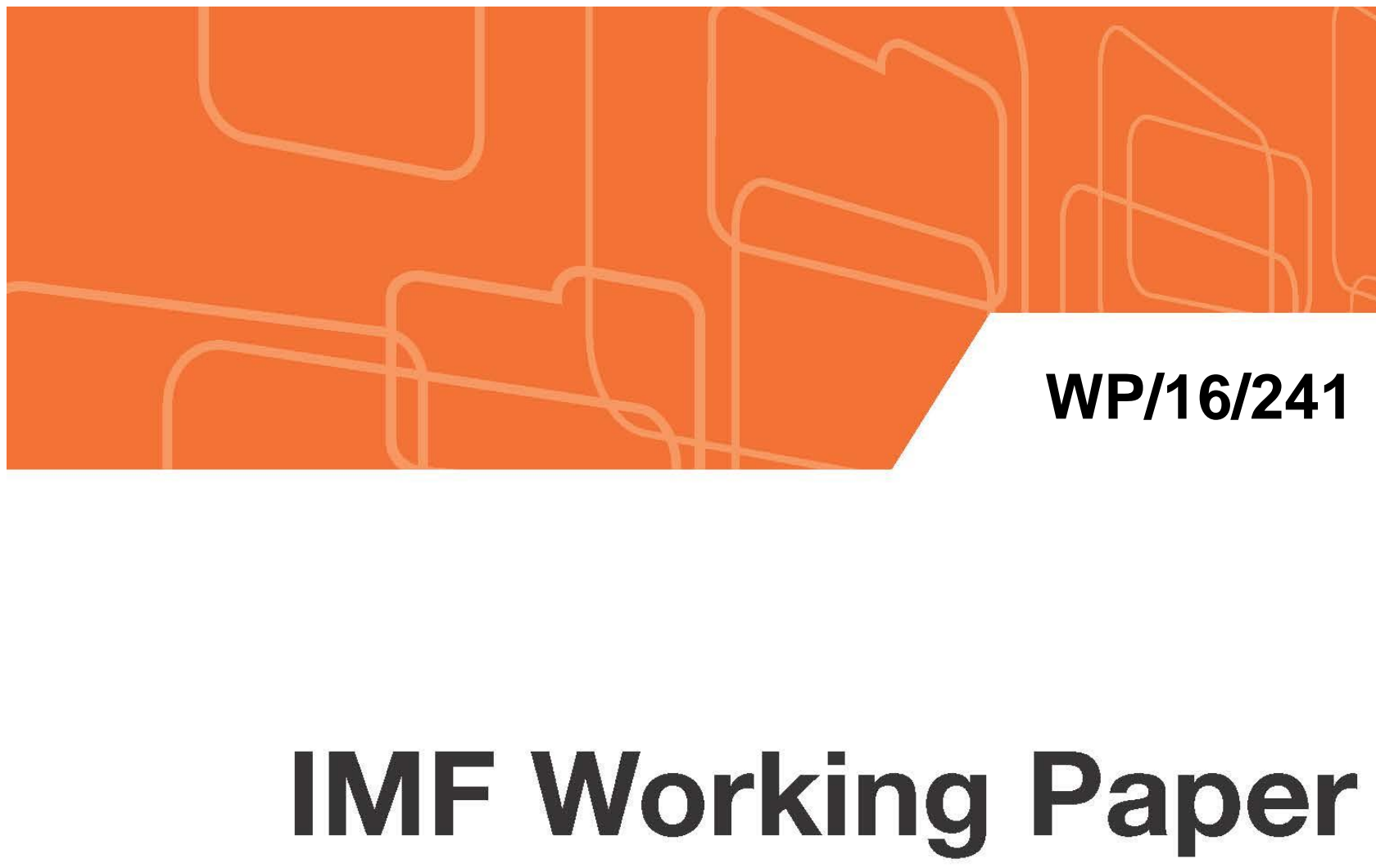

\title{
Output and Inflation Co-movement: An Update on Business-Cycle Stylized Facts
}

by Michal Andrle, Jan Brůha, and Serhat Solmaz

IMF Working Papers describe research in progress by the author(s) and are published to elicit comments and to encourage debate. The views expressed in IMF Working Papers are those of the author(s) and do not necessarily represent the views of the IMF, its Executive Board, or IMF management. 


\title{
IMF Working Paper
}

\author{
Research Department
}

\section{Output and Inflation Co-Movement: An Update on Business-Cycle Stylized Facts ${ }^{1}$ \\ Prepared by Michal Andrle, Jan Brůha, and Serhat Solmaz}

Authorized for distribution by Benjamin Hunt

December 2016

\section{IMF Working Papers describe research in progress by the author(s) and are published to elicit comments and to encourage debate. The views expressed in IMF Working Papers are those of the author(s) and do not necessarily represent the views of the IMF, its Executive Board, or IMF management.}

\begin{abstract}
What are the drivers of business cycle fluctuations? And how many are there? By documenting strong and predictable co-movement of real variables during the business cycle in a sample of advanced economies, we argue that most business cycle fluctuations are driven by one major factor. The positive co-movement of real output and inflation convincingly argues for a demand story. We propose a simple statistic that can compare data and models. Based on this statistic, we show that the recent vintage of structural economic models has difficulties replicating the stylized facts we document.
\end{abstract}

JEL Classification Numbers: C10, E32, E50.

Keywords: Business cycle, demand shocks, DSGE models, dynamic principal components Author’s E-Mail Address: mandrle@imf.org, jan.bruha@cnb.cz, ssolmaz@worldbank.org

\footnotetext{
${ }^{1}$ We thank Jan Babecký, James Costain, Benjamin Hunt, Mika Kortelainen, Douglas Laxton, Junior Maih, Michael Reiter, Antti Ripatti, Daniel Thornton, Jan Vlček, and the participants of the Computational in Economics and Finance 2014 conference, the EABCN 2015 meeting in Oslo, and the European Economic Association 2015 conference for comments on various stages of the paper. The views expressed herein are those of the authors and should not be attributed to the Czech National Bank, the European Central Bank, the World Bank. First version of the paper: October 2012
} 


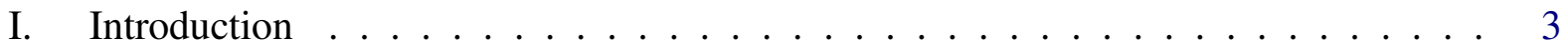

II. Empirical Models and Methods . . . . . . . . . . . . . . . . . . . 5

III. Empirical Results . . . . . . . . . . . . . . . . . . . 8

A. The United States of America . . . . . . . . . . . . . . . . 8

B. Summary Statistics ......................... 11

IV. Some Implications for Macroeconomic Models . . . . . . . . . . . . . . . . . . . 20

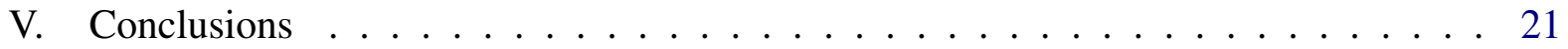

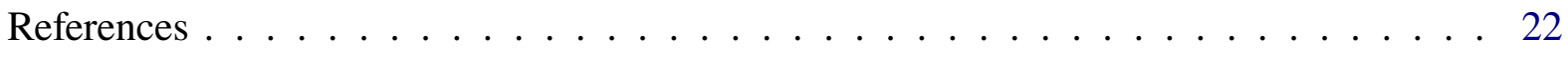

Appendices

A. Additional Graphs . . . . . . . . . . . . . . . . . . . . . . . . 24

B. Data Sources and Specification . . . . . . . . . . . . . . 34 
It is a capital mistake to theorize before one has data. Insensibly one begins to twist facts to suit theories, instead of theories to suit facts. [Sherlock Holmes] ${ }^{1}$

\section{INTRODUCTION}

What are the key business cycle stylized facts, how strong is the co-movement of real and nominal variables, and what are the implication for structural models? In this paper, we attempt to shed some light on these questions, provide an update on business cycle facts, and present some new results on the issue. We illustrate that most of the business cycle fluctuations in advanced and some emerging economies appear as driven by a single major source, a dominant factor. For the purpose of this paper, we label it the 'demand shock,' due to its properties: it can explain strong and predictable co-movement of real and nominal variables over the business cycle. The positive co-movement of real output and inflation, reminiscent of the 'Phillips Curve,' convincingly argues for a demand-driven, not for the technology-driven fluctuations. This, of course, has consequences for designing structural economic models. While both demand and technology-shock-driven business cycle hypotheses may be consistent with one dominant source of co-movement of real variables, the strong co-movement of the dominant component with inflation is a decisive piece of evidence that argues for a demand-driven explanation.

Our empirical approach boils down to multi-country dynamic principal component analysis (DPCA) of data at business cycle frequencies. We focus exclusively on business cycle frequencies, defined as fluctuations between 6-32 or 0-32 quarters for consistency with the literature, and have no intention to explain long-run trends in the data, or high-frequency variations. We use non-parametric spectral analysis to estimate dynamic principal components or, with a slight abuse of terminology, factors, present in the data. ${ }^{2}$ We demonstrate that the first dynamic principal component itself explains up to $80 \%$ of business cycle variation in real and nominal macroeconomics aggregates across a variety of countries.

Despite the frequency-domain nature of the analysis, we present most of our results in the time domain, using simple and intuitive charts. Our 'modeling without theory' empirical strategy follows the spirit of an index (factor) model by Sargent and Sims (1977), investigations of Burns and Mitchell (1946) on the nature of the 'reference cycle', and stylized fact analysis by Kydland and Prescott (1990). Our results differ from the results in the literature due to the economic theory is reflected in the transformation of variables, namely of the inflation series, and emphasis on frequency-specific measures of co-movement. Most notably, the papers mentioned argue there is little or no co-movement of output and inflation, whereas we argue the opposite.

We confirm that the co-movement of macroeconomic variables at business cycle frequency is very strong and stable across countries and time. As most practitioners and

\footnotetext{
${ }^{1}$ Sir Arthur Conan Doyle: Scandal in Bohemia, Adventures of Sherlock Holmes

${ }^{2}$ Henceforth, we use the terms 'factor' and 'component' interchangeably unless stated otherwise.
} 
policymakers know, it simply does not happen that investment plummets while private consumption remains resilient or even rallies during an economic downturn. Again, it does not happen that the unemployment rate drops when output slumps. Yet, what may not be clear from the outset - given all the buzz about the great moderation, the great turbulence, stochastic volatility, or regime switches - is the surprising degree of business cycle fluctuation stability across time and economies that we document in this paper. In short, we elaborate on Cochrane (1994)'s argument that business cycles are "all alike" in several important ways.

The results of our analysis bear consequences for structural macroeconomic models. Our results suggest that in order for the structure of empirical macro-models, notably of Dynamic Stochastic General Equilibrium (DSGE) models, to be consistent with the data, their secondorder moments at business cycle frequencies should possess a clear factor structure with a dominant factor explaining most of the variation. In other words, at business cycle frequencies, the impulse-response functions to shocks needs to be rather similar for shocks with larger variance, or be dominated by one of the shocks with strong real and nominal co-movement. To be clear, we do not claim that everything is driven by a single shock. But we claim that various economic shocks have similar effect on real and nominal variables at business cycle frequencies, and thus can be possibly distinguished one from another only after considering their low- or high-frequency dynamics. ${ }^{3}$

It is the 'reporting of stylized facts' and a-theoretical empirical work that allows us to elaborate on possible misspecifications of DSGE models. We share the view of Kydland and Prescott (1990) that "reporting of facts-without assuming the data are generated by some probability model-is an important scientific activity." Kydland and Prescott comment on a criticism by Koopmans (1957) of the seminal work of Burns and Mitchell (1946) as being "measurement without theory". Koopmans (1957) essentially argues that an analysis without a formal economic model is not very useful. Today, data interpretation is often carried out through the lenses of DSGE models. However, estimating a DSGE model would not necessarily help us to uncover and better understand the sources of misspecification or the strong empirical regularities in the data, as long as the model is not fully consistent with it.

There are three original contributions of the paper. First, great regularities in Post-War business-cycle co-movements of key macroeconomic variables across multiple economies are documented. Going beyond cross-correlations, the dynamic principal component analysis and the applied data transformation technique help to identify that there is just one dominant factor behind the real co-movement, typically explaining more than two thirds of cyclical fluctuations. Second, the analysis of both real variables and inflation reveals their tight comovement - sometimes doubted in the literature - and allows us to label the dominant principal component as a 'demand factor.' The use of inflation — instead of the price level—and its deviations from the trend or long-term inflation expectations is a key ingredient for our results. Third, the results of our agnostic analysis carry important implications for theoretical economic models regarding the number of shocks and the properties of a dominant structural shock in a way that has not yet been demonstrated.

\footnotetext{
${ }^{3}$ A companion paper by Andrle, Brůha, and Solmaz (2016) builds on empirical findings in this paper and formulates misspecification tests for DSGE models.
} 
There are also caveats to our conclusions and our methodology. First, our approach is not driven by any particular model and is mostly a statistical summary of data. Nevertheless, our approach is guided by economic reasoning with regards to variable selection and transformation, which allows us to obtain novel results. Second, our analysis focuses on cyclical frequencies of the data. We do not claim this is the best definition of a business cycle, or that the trend components are 'potential' or 'equilibrium' values of the variables considered. We stick to a standard definition of cyclical frequencies in the literature. Third, we illustrate strong comovement of real and nominal variables at cyclical frequencies but we acknowledge that lowfrequency dynamics does not feature nearly as much co-movement as the cyclical ones. It is also quite possible that quite distinct economic shocks have similar dynamics at cyclical frequencies and can be distinguished only at other frequencies.

The structure of the paper is the following: In Section II we introduce and discuss the methods used in the paper. In Section III we describe the results for the U.S. and summarize the evidence for the rest of the countries in our sample. In Section IV we assess the implications of our results for macroeconomic modeling and in Section V we conclude. Additional materials, such as non-core graphs, sensitivity, or robustness checks are included in the Appendix.

\section{EMPIRICAL Models AND MethodS}

Our main tool is a dimensionality-reduction technique: the principal component analysis, (PCA). PCA aims at decomposing observed time series, $x_{i, t}$, using the following representation:

$$
x_{i, t}=\chi_{t}+\xi_{i, t},
$$

where $x_{i, t}$ is the observed series, $\chi_{t}$ is the low-dimensional common component, spanned by principal components. The term $\xi_{i, t}$ is the idiosyncratic noise, which is uncorrelated with the common component $\chi_{t}$, and only weak correlation among elements of $x_{i, t}$ is allowed. A set of $K$ time series is fully explained by $K$ principal components, with potentially a small number of principal components explaining most of the dynamics. We apply PCA both to time and to frequency domains as we are interested only in cyclical frequencies.

There are various forms of PCA. Static principal component analysis (SPCA) is based on eigenvalue decomposition of the covariance matrix and does not take into the account leadlag relationship between among variables. Dynamic principal component analysis (DPCA) introduced by Brillinger (1981) is based on the eigenvalue decomposition of the spectral density matrix and can be applied both in time and in frequency domains. In the time domain, the two-sided representation by Forni and others (2000) can account for lead-lag relationships. Because of this property, DPCA is our default choice, while SPCA in the time domain results are used only as a robustness check. ${ }^{4}$

\footnotetext{
${ }^{4}$ In fact, in very small samples, it could happen that even under nontrivial lead-lag relationships, SPCA could fit data better than DPCA because of an imprecise estimation of the spectral density.
} 
Our approach in the time domain is straightforward: we isolate cycles using both the band-pass filter (Fitzgerald-Christiano) and high-pass Hodrick-Prescott filter with conventional values of parameters for quarterly frequencies to maintain comparability to the literature. Then, we apply PCA in the time domain to the isolated cycles and ask about the dimension of the common component that spans sufficiently well the observed time series. We follow Stock and Watson (2002) and use their goodness-of-fit statistics. In particular, let $\chi_{i, t}^{k}$ be the common component for the series $x_{i, t}$ estimated using $k$ first principal components, then the statistics reads as:

$$
\mathfrak{R}^{2}(k):=1-\sum_{t=1}^{T}\left(x_{i t}-\chi_{i t}^{k}\right)^{2} / \sum_{t=1}^{T}\left(x_{i t}-\bar{x}_{i}\right)^{2},
$$

where $\bar{x}_{i}$ is the sample mean of $x_{i, t}$. As noted above, DPCA is our default choice to account lead-lag relationship among data; nevertheless, we also applied the SPCA to these transformed series. ${ }^{5}$

Frequency domain DPCA starts with the estimation of the multivariate spectral density $\Sigma_{x}(\omega)$ of the observed process $x_{t}$, from which the spectral density of the common component $\chi_{t}$ is obtained by selecting dominant eigenvalues. By selecting the dominant eigenvalues at each frequency, an estimate of the spectral density $\Sigma_{\chi}(\omega)$ of the common component is obtained. Therefore, it is natural to propose the following statistics. Let $\left\{\lambda_{(i)}(\omega)\right\}_{i=1}^{n}$ be ordered eigenvalues of $\Sigma_{x}(\omega)$ at frequency $\omega$. Since $\Sigma_{x}(\omega)$ is positive semi-definite for each frequency $\omega$, all eigenvalues are non-negative. Therefore, to evaluate the degree of comovement in the data, $x_{t}$, we consider the following statistics:

$$
S_{x}(\omega, k):=\sum_{i=1}^{k} \lambda_{(i)}(\omega) / \sum_{i=1}^{n} \lambda_{(i)}(\omega),
$$

which is the percentage of variability explained by $k$ principal components at frequency $\omega$. The analysis in the frequency domain is immune to possible criticism of pre-filtering of the time series by statistical filters. That being said, we find it useful to note that the often-heard opinion that the use of statistical filters, say the Hodrick-Prescott filter, always causes spurious cycles is misguided; see Pollock (2013) who formally proves that "this idea is largely mistaken."

The computation of the spectral density estimate using raw, unfiltered data is a subtle issue since some of our macro variables are non-stationary. When working with nonstationary data, spectral estimates cannot be carried out without some modification. We use the non-parametric Bartlett approach ${ }^{6}$ on first log differences (when meaningful), which renders the problem stationary. This does not pose a problem for the measure (2), as it is invariant

\footnotetext{
${ }^{5}$ The main reason for dynamic PCA is a time shift of unemployment with respect to output (Okun's law) and of inflation and interest rates when included in the computations. The lead-lag relationships used by DPCA increase the fit of the model, but the gain in fit is not dramatic. When we apply the static principal component analysis to our data the results and implications are qualitatively unchanged with slightly lower fit.

${ }^{6}$ In our empirical analysis we use exactly the same approach in estimating the multivariate spectral matrix, with the same Bartlett non-parametric approach and the same setting of the smoothing window as suggested by Forni and others (2000).
} 
with respect to first-differencing all series. Indeed, it can be shown that:

$$
S_{Y}(\omega, k)=S_{\Delta Y}(\omega, k),
$$

for all frequencies $\omega$ such that both sides are defined. It implies that for non-stationary $I(1)$ time series, the statistics (2) can be estimated for first differences of series and this holds for all $\omega \neq \pm 2 \pi n$ for $n \in \mathbb{N}_{+} \bigcup 0$. Moreover, some other statistics of interest, such as coherence, also remain unchanged if both series are pre-processed by the first-difference filter. Formally, if $\mathcal{C}_{x, y}(\omega)$ is the coherence between series $x$ and $y$, then, it holds that:

$$
\mathcal{C}_{x, y}(\omega)=\mathcal{C}_{\Delta x, \Delta y}(\omega),
$$

for all $\omega$ for which both expressions are defined. See, for instance, Koopman (1974, pp. 149).

We focus explicitly on business cycle frequencies. For each country in our sample, we consider the following set of variables: real GDP, real consumption, real investment, real exports, real imports, the unemployment rate, and the short-term interest rate. First, we investigate the co-movement among these real variables. For our analysis, it is also crucial how the cyclical dynamics in real variables are related to the cyclical dynamics of inflation. We do it again in two ways. In the time domain, we compare the dynamics of the first dynamic component to the dynamics of inflation deviation from its trend (henceforth called the inflation cycle). We compare the dynamics of the inflation cycle to the output cycle. ${ }^{7}$ In the frequency domain, we compute and report the coherence between inflation and output as well as between inflation and the isolated first dynamic component.

We use the trimmed-mean inflation as our preferred measure of inflation. Trimmedmean inflation eliminates outliers and lowers high-frequency variation without ex-ante eliminating particular components of the consumer basket. ${ }^{8}$ Unlike linear filters, the trimmedmean is not dependent on past and future observations, can be computed in real-time with zero revisions. However, with the exception of the U.S. and Australia, we had to construct our own trimmed-mean inflation measures with data available only from early 90's using the Haver Analytics database.

\section{So, why don't we always put inflation directly into the dynamic principal component} model? The only reason is that trimmed-mean inflation data for most countries span a smaller sample size than macroeconomic data on other variables, which would restrict our analysis too much. This is why we choose to compare inflation dynamics with the common component estimated on real variables instead. Inflation, therefore, does not affect the estimates of the unobserved principal components. The only exception is the USA, where we estimate the principal components jointly and present the results.

\footnotetext{
${ }^{7}$ The economics behind this process can be understood by considering a country with an explicit path of the inflation target. It is then the deviation of inflation from its target that is related to the output cycle, not the overall level of inflation. This an extremely important consideration for our analysis and is discussed in greater detail below.

${ }^{8}$ Andrle, Bruha, and Solmaz (2013) show this point using euro-area data. Elimination of high-frequency variation using median inflation (i.e., the extreme case of trimmed means) has been suggested also by Meyer and Zaman (2013) in the forecasting context.
} 


\title{
III. EMPIRICAL RESULTS
}

\begin{abstract}
In this section, we document the strong co-movement among cyclical components of main macroeconomic variables and inflation. We show this for the United States and for the cross-section of advanced countries. The United States is an obvious choice for it's 'benchmark' status earned by the size of the economy and length and quality of the statistical data. Summary statistics for 28 OECD countries are provided in a dedicated section and the results for Germany and Japan can be found in the Appendix, as examples of other large and open economies.
\end{abstract}

\section{A. The United States of America}

In the case of the U.S. economy, our empirical findings are the most robust ones. Figure 1 clearly demonstrates in the time domain that the first dynamic principle component can explain a great portion of the variation of the business cycle in the U.S. Virtually every variable, with the exception of real exports, and short-term interest rates is explained by more than $80 \%$ using a single dynamic principal component. Further, Figure 3 demonstrates a strong co-movement of output and the dominant factor with the cyclical dynamics of median inflation. The short-term "Phillips Curve" in the United States appears to be alive and well!

Given the strong explanatory power of the common component, it is particularly interesting to seek a narrative for deviations of variables from this common cycle. For instance, the private consumption slowdowns in 1992 or 1997 are notable deviations from the 'reference cycle'. In the case of the short-term interest rate this is due to the fact that monetary policy is not easily described as following some sort of pro-active interest-rate or 'Taylor' rule in late 1980's, a fact well understood given about the FED policy under the leadership of chairman Volcker. The case of exports is different. Since the U.S. exports are the imports of their trading partners, the exports should be well approximated by trade-weighted combination of explained import components of partner regions, which it is, see Figure 17. ${ }^{9}$ As such, DPCA by definition ascribes more variation to second and third principal components to explain the remaining dynamics.

In the frequency domain-without pre-filtering in the time domain-the results hold as well. Figure 4 shows the portion of the spectral density explained by the first two dynamic principal components over the whole range of frequencies. Apparently, the fit of the spectral density using one principal component over the business cycle is great especially for imports and investment. For exports, one needs the second principal component, which makes the fit of the spectral density of exports almost perfect over business cycles.

\footnotetext{
${ }^{9}$ To investigate this hypothesis we used data from the IMF's Global Projection Model database and computed implied export gap using constant trade weights and imports of China, the euro zone, Emerging Asia, Japan, Latin America, and Remaining Countries. Fig. 17 presents the results and suggests that more formal and detailed investigation of co-movements and spillovers could explain the data in a more comprehensive way. A multi-country restricted factor model is left for our future research.
} 
We present the results for both Christiano-Fitzgerald and Hodrick-Prescott filters. The key difference is that the HP filter does not exclude high frequencies of the data and the filter cutoff between low and cyclical frequencies is not as sharp as for the Christano-Fitzgerald band pass filter. The results for the HP filter (both in time and frequency domain) show that the results holds also for data pre-filtered by this popular filter in both the shorter and full sample, see Figure 2 and Figures 10 and 11 in the Appendix.

Surprisingly, the results are not affected much by extending the sample to before the 'Great Moderation' episode. We estimated the DPCA model for data since 1966 which features two periods that most economists agree contain is a different volatility in the macroeconomic aggregates in the U.S. - a period of volatile business cycles, followed after mid-1980's by a Great Moderation period, put abruptly to an end by the Great Recession started in 2007. The relative explanatory power of the first principal component is changed a little bit, with an expected deterioration of the short-term interest rate fit before 1985 - an era of volatile policy rates, Gold-Exchange Standard, and two important oil price shocks. The first principal component changes its variance but the filter loadings (coefficients of the model) are constant. That means that relative variances among real variables cycles have not changed significantly neither during the Great Moderation period nor during the recent Great Recession. The sample starts in 1966Q2 and ends in 2015Q4 (see Figure 9 in Appendix).

The simple calculation with extended sample for the U.S. has important consequences for econometric models with time-varying coefficients. It seems clear that acknowledging a distinct volatility in the two portions of the sample. On the other hand, the dynamics driving relative variance and relative co-movement among the key variables seems essentially time invariant.

\section{Co-Movement of Real and Nominal Variables:}

A thorough consideration of inflation dynamics is key to our analysis and an important piece of evidence about the importance of demand shocks. It is the explicit use of inflationinstead of the price level - and considerations about the implicit and subsequently explicit inflation target of the FED, that allow us to demonstrate the close co-movement of output and the deviation of inflation from the target. Central banks today do not operate in a price-level targeting framework but rather in an inflation-targeting framework. Clearly, low-frequency movements of inflation are driven by perceptions of the inflation target, as embodied in longterm inflation expectations, or long-term nominal bond yields. For consistency among countries, the cyclical component of inflation is obtained using a band-pass and HP filter in our baseline calculations. However, using the ten-years-ahead long-term inflation expectations ${ }^{10}$

\footnotetext{
${ }^{10}$ Ten-year ahead long-term inflation expectations are obtained from Survey of Professional Forecasters (SPF) at Philadelphia FED. The FRB/US measure of implicit inflation target, variable PTR in the FRB/US
} 
though would lead to a similar removal of the 'trend' process from inflation, see the Fig. 8. The high-frequency dynamics of core inflation are lower than in the case of headline CPI, since our measure is the Cleveland's FED trimmed mean inflation. ${ }^{11}$

Viewed through the lens of our analysis, there is little evidence for a nominal-real dichotomy: inflation lags the output cycle in a relatively stable and predictable way. The strength of the output-inflation co-movement can be recognized from Fig. 3, which depicts the cyclical component of core inflation and the normalized first dynamic principal component (essentially the output cycle). ${ }^{12}$ The figure also shows the estimated coherence along with 95 percent confidence intervals. ${ }^{13}$ between trimmed inflation and output (and between trimmed inflation and the first estimated dynamic component). Unlike in the case of real variables, the conduct of monetary policy following chairman Volcker's appointment led to a lower variance of inflation around the long-term inflation expectations that we have adjusted by normalizing the series to Great Moderation average variance. Yet, apart from the amplitude change, the co-movement between inflation and real variables is preserved.

Our results thus indicate a strong and stable co-movement between key real macro variables and inflation over the course of a business cycle. The first dynamic principal component has such dominant explanatory power that we do not venture the identification of other type of macroeconomic disturbances. The positive co-movement of the dominant component (and output) with the inflation cycle motivates the label of the component as a 'demand factor' or the demand shock. We do not observe the demand shocks directly and cannot link it to particular events, of course. Looking close enough, all cycles will look as caused by a different event, just to look more or less alike when viewed from a larger perspective, echoing the conclusions of Cochrane (1994) or Kindleberger and Aliber (2005), among others, that the more things change, the more they stay the same.

\section{It is important to point out that data transformations are important for seeing clear} results. If growth rates were used instead of a band-pass filter, the DPCA fit would deteriorate, which can be seen from Figure 5. The logic is clear as soon as one looks at the graph of the transfer function of the difference operator, $1-L$, which amplifies high frequencies relative to business-cycle and the low frequencies. Nevertheless, despite the deterioration of the fit, the comovement among real variables is still there, although not as impressive as for cyclical components of real variables. Figure 16 in the Appendix presents normalized growth rates of GDP components to highlight that strong co-movement is easily discernible.

\section{In the case of inflation, the argument that the economic theory and the monetary policy regime have a strong say in terms of data transformation is crucial. Namely, linking devi-}

model, can also be used as a proxy for the unobserved inflation target (we thank Robert Tetlow for providing the data) as it reaches the sample before SPF 10Y expectations; see Andrle (2012) for empirical analysis and demonstration of consistency of New-Keynesian expectational Phillips curve with observed data dynamics. What our analysis also says is that while cyclical dynamics around long-term inflation expectations seems driven by the economic cycle, the dynamics of long-term inflation expectations are a different issue altogether.

${ }^{11}$ The series has been extended by splicing the old trimmed mean series and the new, revised trimmed mean, due to negligible differences in the overall dynamics.

${ }^{12}$ The plot is phase-aligned, i.e. the inflation cycle is shifted by a mean lag.

${ }^{13}$ Computed using wild bootstrap, see Wu (1986) 
ation of inflation from its target (and thus long-term expectations) to output or unemployment dynamics. Given the very tight fit of the Okun's law, the specification of the Phillips Curve in terms of output or unemployment is almost equivalent. The importance of the distinguishing long-term (inflation target) and cyclical inflation dynamics is easy to illustrate in the case of inflation-targeting countries that underwent a disinflation process like Canada, the Czech Republic, Poland, and others. Without knowing the value of the inflation target, relating the inflation and the cyclical stance of the economy, i.e. the output gap, is meaningless. In the case of the United States, the relationship of the inflation and the output cycle is clearly visible after the low-frequency dynamics or long-term inflation expectations (e.g. ten-years-ahead inflation expectations from the Survey of Professional Forecasters) removed from the inflation series.

Finally, the length of the U.S. data enables us to plug the trimmed mean inflation directly into the DPCA analysis. The results are available in Figure 12, showing the fit in the time domain for HP cycles (results for the band-pass cycles look like similar). For output, consumption, investment, and unemployment, the one principal component produces an excellent fit. The common component based on the first principal component for exports, the shortterm interest rate, and trimmed inflation explains about 50\% of volatility. The relatively low explanatory power of the first principal component is due to the high volatility of these series during the 1960s and the 1970s, nevertheless, filter loadings have the same sign. We conclude that this exercise confirms our finding that the relative variance of some variables may change, but the co-movement is stable.

\section{B. Summary Statistics}

In this subsection, we report summary statistics for all countries in our dataset. We have collected data for a list of advanced and several emerging market countries at a quarterly frequency. The list consists of: Australia, Austria, Belgium, Canada, the Czech Republic, Denmark, Finland, France, Germany, Hungary, Ireland, Italy, Japan, Korea, Luxembourg, Mexico, Netherlands, New Zealand, Norway, Poland, Portugal, Slovakia, Slovenia, Spain, Sweden, Switzerland, Turkey, the U.K., and the U.S. Our benchmark analysis starts from the year 1985. The choice of this year is motivated by the change in relative volatilities of inflation and real activity (Great Moderation) in developed countries around the mid-1980s. Nevertheless, we carry out our exercise with a longer sample for countries where a larger sample is available. The co-movement among real variables remains stable, even when the larger sample is used. We also find a cyclical similarity of inflation and real activity when the change in their relative volatilities is taken into the account.

First, we report the box plots of how the model fits the co-movement in cyclical parts of real variables. ${ }^{14}$ Figure 6 shows the fit for the post 1985 sample for the first three dynamic

\footnotetext{
${ }^{14}$ Boxplots are organized as follows: on each box, the central mark is the median, the edges of the box are the 25th and 75th percentiles, the whiskers extend to the most extreme data points that are not outliers, and the outliers are plotted individually. Observations are defined as outliers if they are larger than $Q_{75}+1.5\left(Q_{75}-Q_{25}\right)$ or smaller than $Q_{25}-1.5\left(Q_{75}-Q_{25}\right)$, where $Q_{25}$ and $Q_{75}$ are the 25th and 75th percentiles.
} 
components (organized by rows) and for the two commonly used filters (Christiano-Fitzgerald band-pass filter and HP filter - organized by columns). Apparently, for most countries, already the first dynamic principal component explains most of the dynamics in output, investment, imports and unemployment. The first two dynamic principal components then explain a high share of the dynamics in all variables. Figure 15 in the Appendix depicts the same exercise for all data in our sample. Apparently, the fit is robust for the inclusion of the period before 1985 , for countries where available. The analysis reveals that for all countries the largest dispersion of percentage explained is for exports, short-term real rate, and consumption as indicated in the discussion above.

The co-movement of inflation and real variables also seems rather strong for all countries in the sample. Figure 7 reports the summary results on the co-movement between the inflation cycle and cycles in real variables for all countries in the sample. It reports the coherence and cross-correlation of the inflation cycle with output and of inflation with the first dynamic principal component. The results indicate relatively high co-movement between inflation and the real economy over the business cycle. ${ }^{15}$

\footnotetext{
${ }^{15}$ Interestingly, for each country in our sample, there is a lag $k \in(0, \ldots, 4)$ for which correlation between cyclical inflation and the cyclical component of output is positive and significantly different from zero at the 5\% level.
} 
Figure 1. U.S.: Cyclical components, data and fit with the DPCA (CF Bandpass)
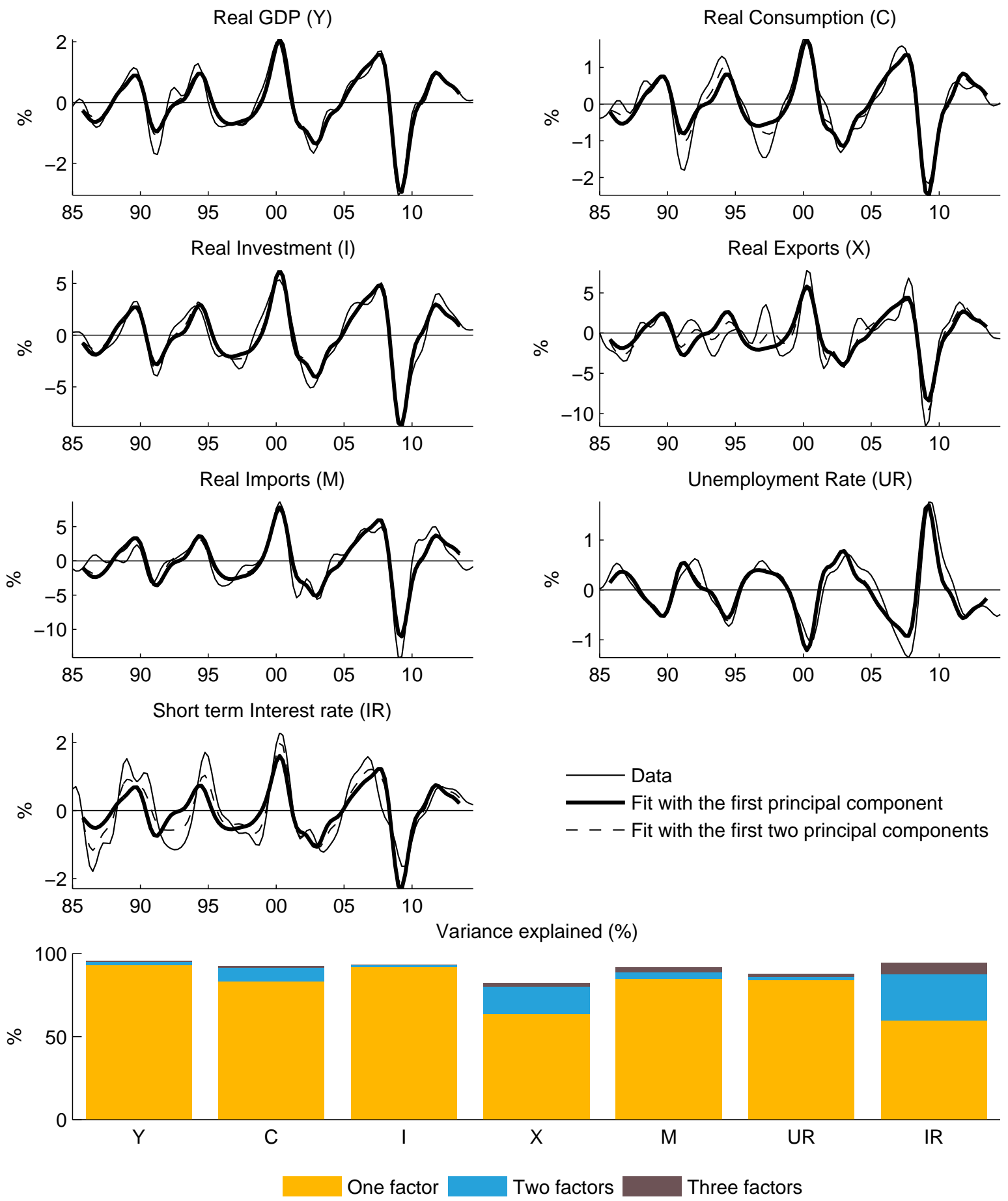
Figure 2. U.S.: Cyclical components, data and fit with the DPCA (HP filter)
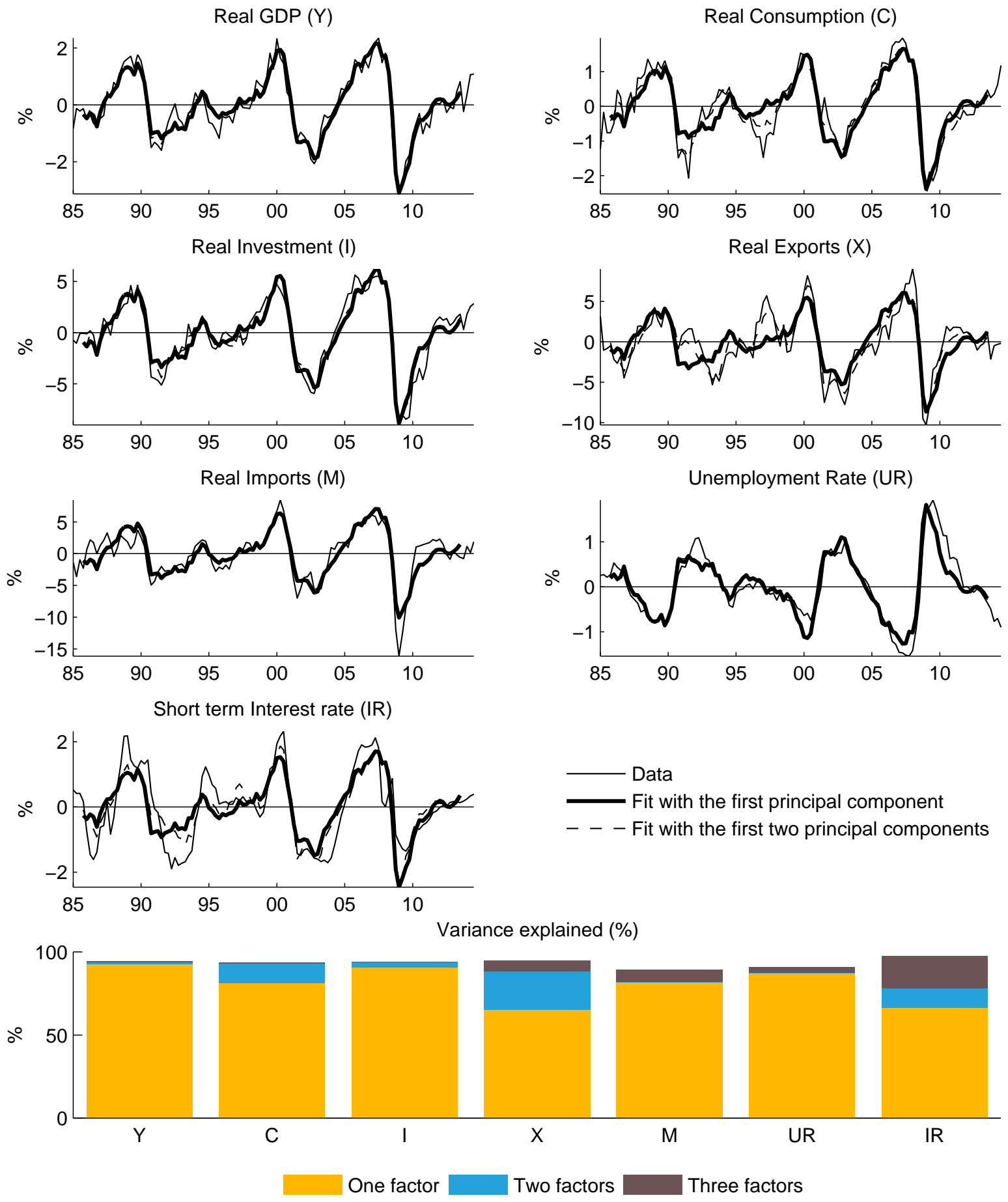
Figure 3. Inflation and real economy - the U.S. (post 1985)
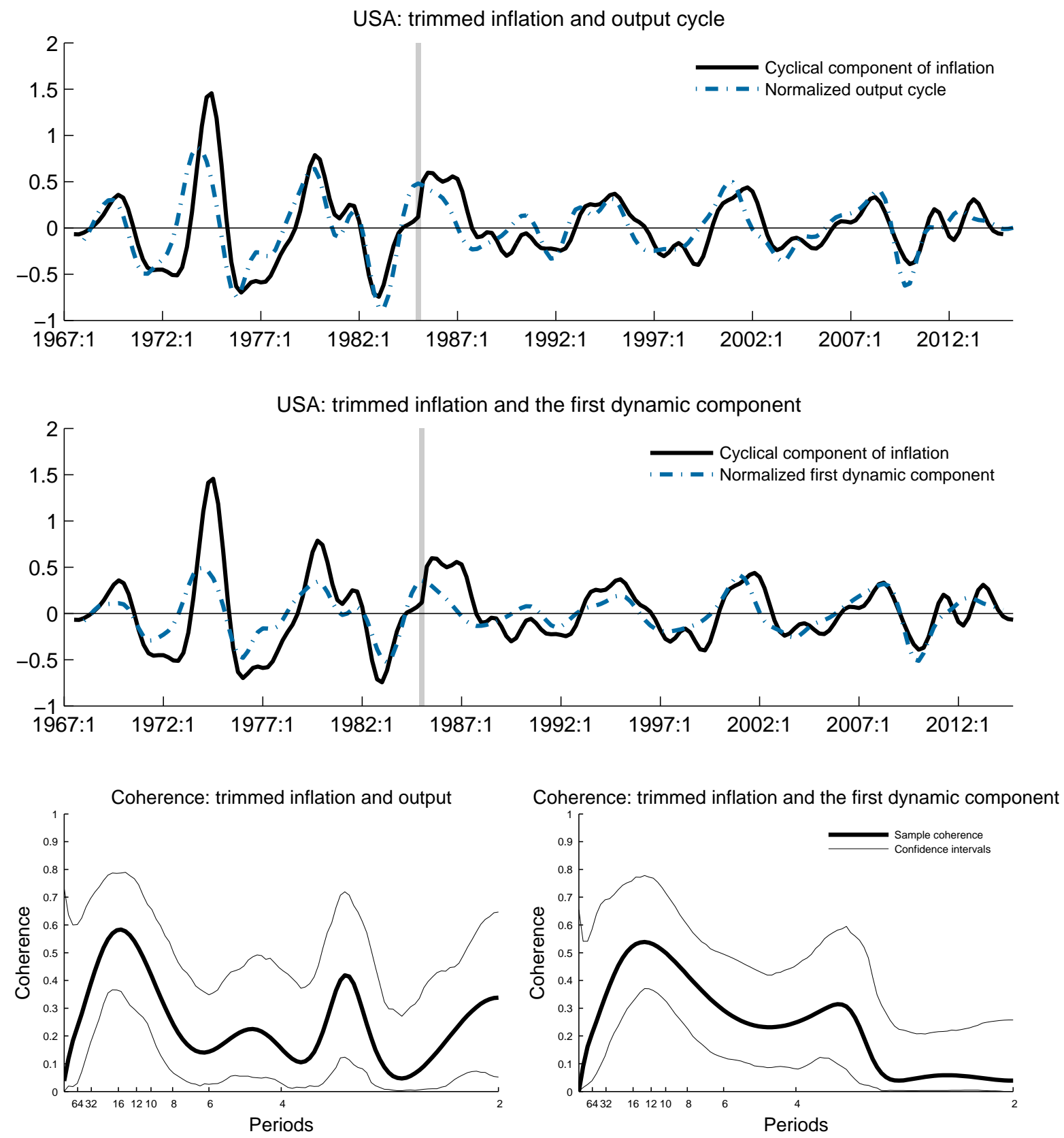
Figure 4. U.S.: Share of spectral density explained

Real GDP (Y)

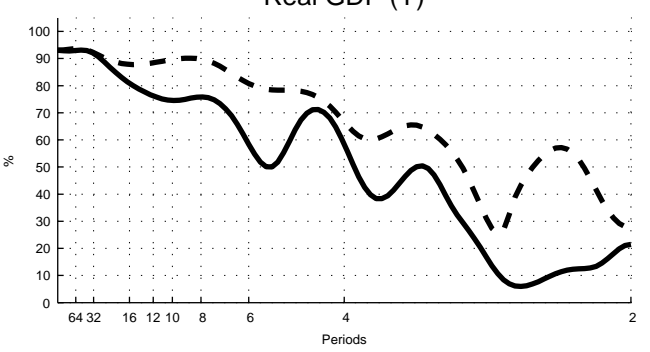

Real Investment (I)

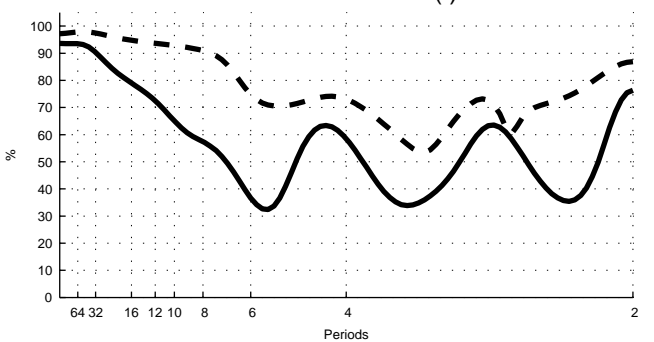

Real Imports (M)

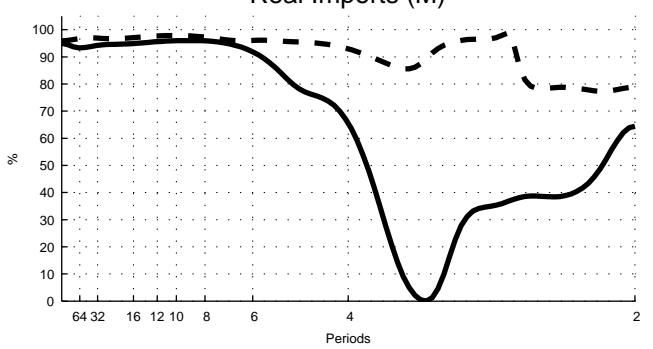

Short term Interest rate (IR)

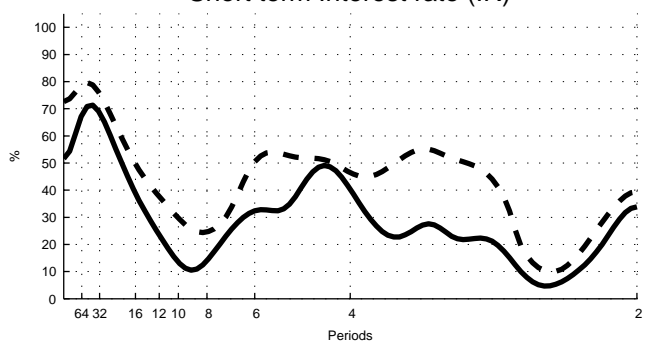

Real Consumption (C)

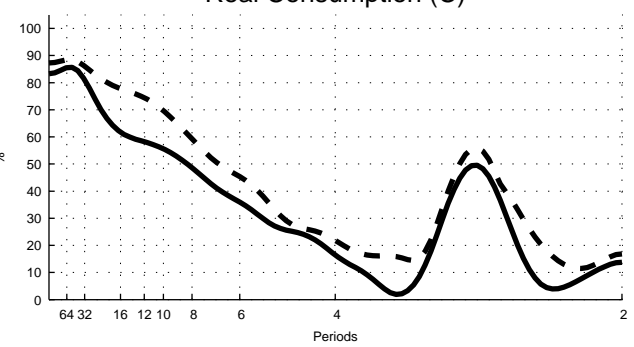

Real Exports (X)

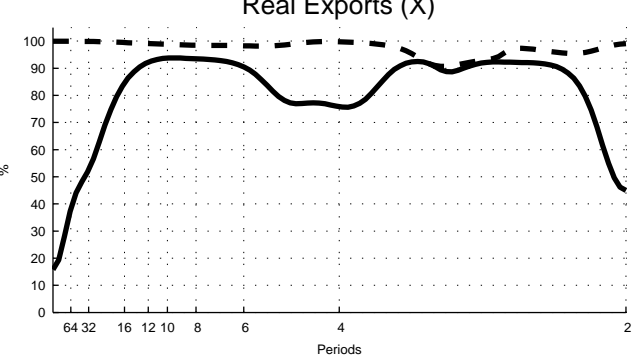

Unemployment Rate (UR)

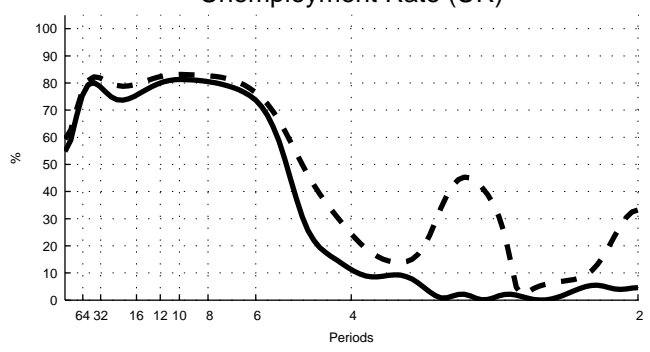

The first common component

- - - The first two common components 
Figure 5. Growth rates: data and fit with the DPCA - the U.S.
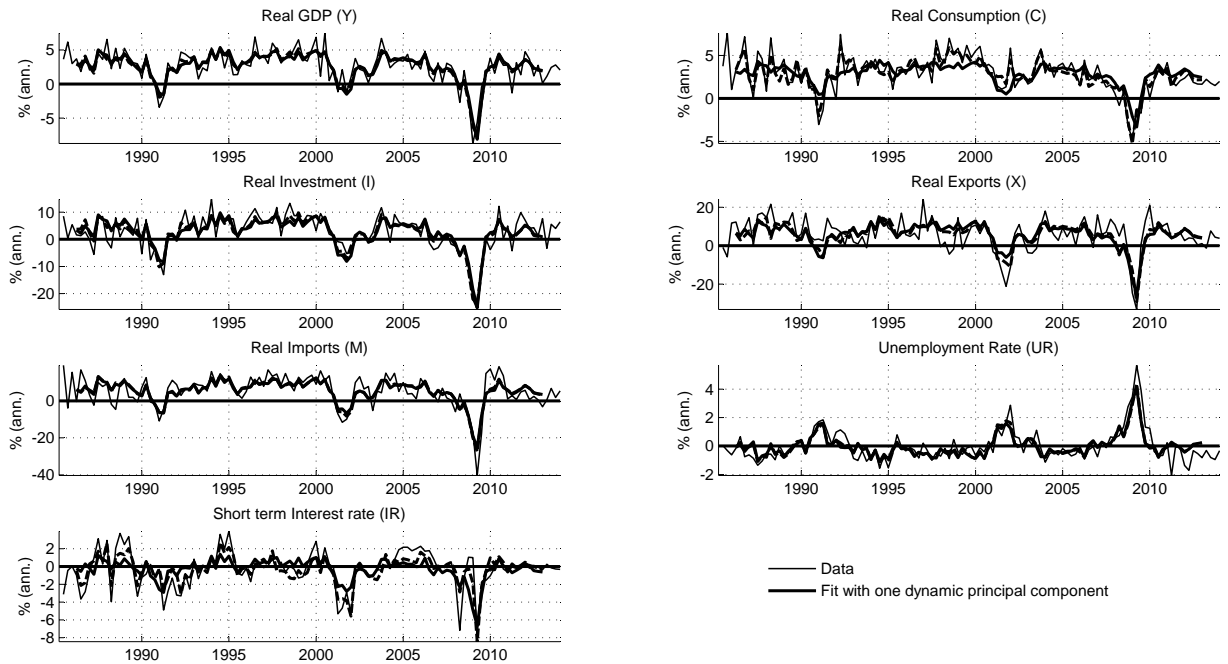

Data

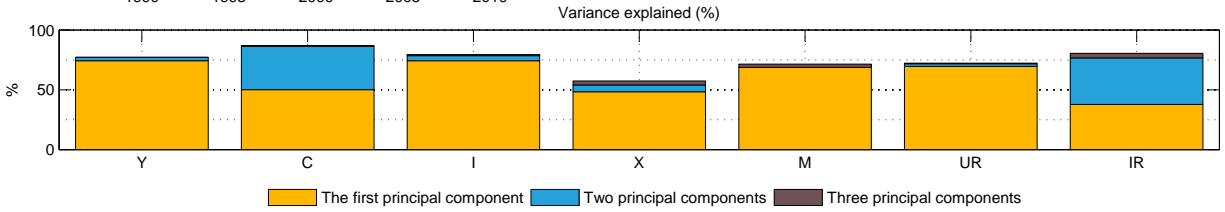


Figure 6. The boxplot summary statistics
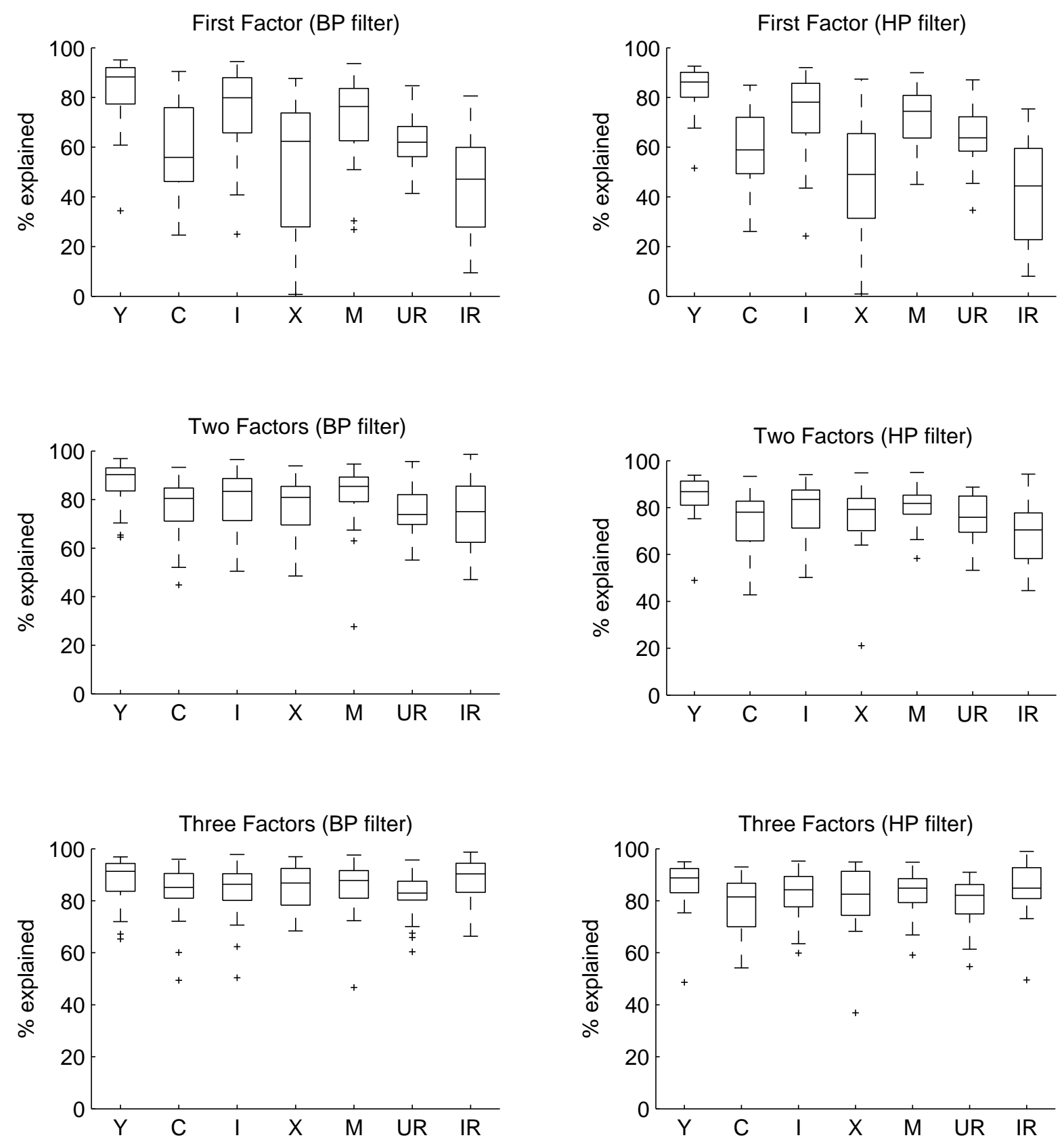
Figure 7. The summary statistics: coherence and correlations between inflation and real activity

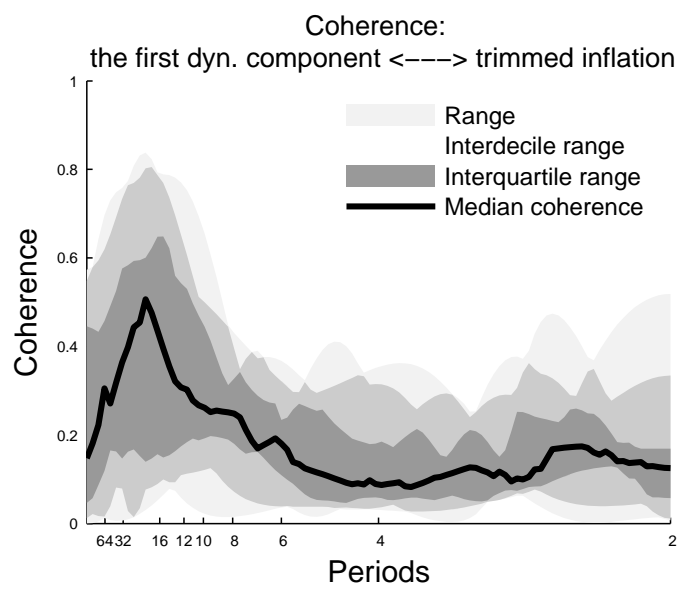

corr(First Dyn. Component $t_{t+k}$, trimmed inflation ${ }_{t}$ ) (band pass)
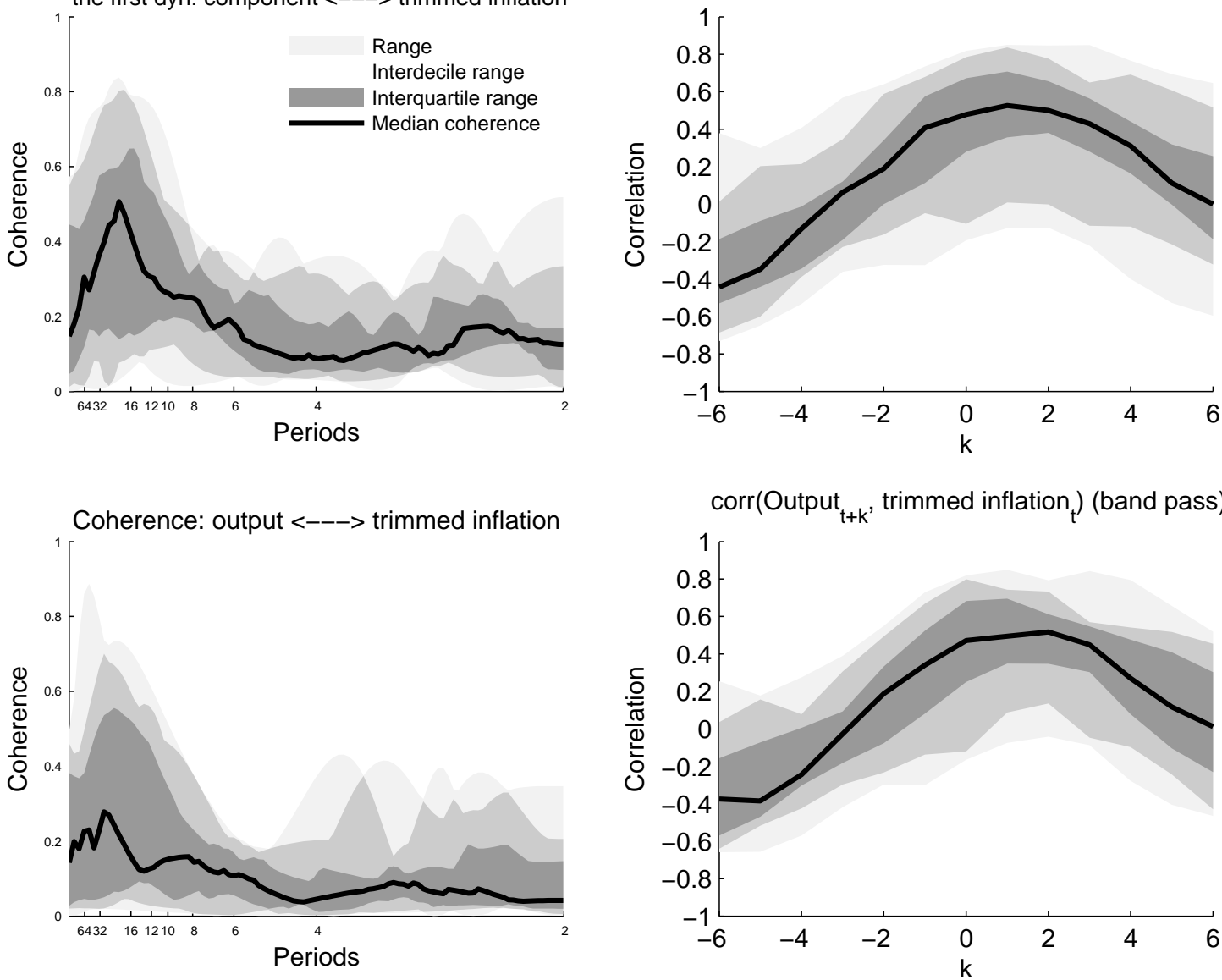


\title{
IV. SOME IMPlications FOR MACROECONOMiC MODELS
}

\begin{abstract}
The strong co-movement of real and nominal variables has implications for structural economic modeling. In principle, empirically successful models should be able to mimic the correlation structure consistent with a dominant principal component for the variables considered at business cycle frequencies. More specifically, an economic model that does not feature a structural shock that dominates the cyclical frequencies of consumption, investment, output, hours worked, and inflation is very likely to be misspecified. ${ }^{16}$ This amounts to both (i) the variance contribution of the shock and (ii) the direction of co-movement of relevant variables.
\end{abstract}

When models lack a dominant structural factor with the above-mentioned properties, the misspecification will lead remaining structural shocks to be cross-correlated. The requirements on models are rather strict. At business cycle frequency, not only should a single factor be dominant and result in a positive co-movement of real variables with inflation but little leeway is allowed for the shape of the impulse-response functions to such a shock in terms of amplitude and phase. For instance, in the United States, investment volatility relative to output must be around four, the 'Okun's coefficient' for unemployment is around half, and the relative variance of the consumption cycle to output is slightly lower than one, with an identical direction of the response. Since the data feature this correlation pattern, then a misspecified structural shock inevitably leads to cross-correlation of other shocks. When models with cross-correlated estimated 'structural shocks' are used for structural interpretation of the data, the results appear as if multiple shocks offset each other on a rather regular basis. ${ }^{17}$

\section{Our analysis suggests several intuitive 'smell tests' to asses model performance and} misspecification. One can devise two specification tests for the model - one ex-ante, based on the principal-component space of the model, and the other ex-post, based on cross-correlation of estimated shocks. Before a thorough analysis of shocks and measurement errors it is critical to check if the model dynamics can explain business cycle dynamics with one dominant source of variance. That can be the case if the model-induced principal-component space is close to the principal-component space of the data and if the impulse-responses 'make sense' in light of robust stylized facts on co-movement that many practitioners are well aware of. A companion paper Andrle, Brůha, and Solmaz (2016) discusses the implications of our findings for empirical models in more detail and proposes misspecification tests.

\footnotetext{
${ }^{16}$ Again, this holds for business cycle frequencies. There could be different shocks that have nearly identical response at cyclical frequencies and are identified by low or very high frequencies only.

${ }^{17}$ For instance, a $2 \%$ increase in output will appear tobe due to positive $10 \mathrm{pp}$ the contribution of productivity shocks and negative $8 \mathrm{pp}$ due to the contribution of the labor supply shock, etc.
} 


\section{Conclusions}

In this paper, we provide an empirical investigation of the sources of economic fluctuations - their nature and their implications for economic modeling and policy analysis. We reach a conclusion that business cycle dynamics of key macroeconomic data can be largely explained by a single source of variation. Since this dominant unobserved principal component behind the business cycle explains positive co-movement of output cycle and inflation, we label the principal component the 'demand factor.' We describe the properties of this demand factor and note that structural economic models have great difficulties delivering structural shocks resembling our robustly-estimated dominant principal component.

Our analytical approach allows us to reach strong conclusions with relatively modest identification assumptions. We employ a straightforward dynamic principal component analysis to analyze key real and nominal macroeconomic data for OECD countries. The analysis decomposes data into a set of orthogonal contributions of a number of components. The first dynamic principal component clearly dominates in terms of explained variance, so other components are not explicitly analyzed or identified. The effects of the dominant component also satisfy the sign restriction one would expect from an broadly-understood "demand shock," namely positive co-movement of output and inflation, which renders the factor its label - a demand factor. We document that the set of stylized facts leading to a demand factor continues to hold across a set of OECD countries. Further, our findings are invariant to the use of both time- and frequency-domain techniques, which do not rely on time-domain filtering.

The absence of a real-nominal dichotomy is an interesting result, highlighting the importance of variable definitions in the analysis as a shield to misspecification. We have illustrated that there is positive co-movement of output and inflation at business cycle frequencies, a key result allowing us to argue for a demand-like explanation of business cycles. Why do the Phillips curve estimates or dynamic factor model analysis usually fail to find a stable relationship, claiming a real-nominal dichotomy, while our results do find it? The key is our focus on business cycle frequency and thus data transformation. Cyclical dynamics of inflation are akin to a deviation of inflation from an inflation target or long-term inflation expectations and theory predicts this 'inflation gap' should positively co-move with the cyclical component of output. We do find this positive relationship. If we were to follow the literature and use the first difference of inflation (to render it stationary) with demeaned GDP growth or gap, the task of finding a positive relationship would be rather futile due to the over-differencing transformation that amplifies high-frequency disturbances in the data and has weaker theoretical support.

The existence of a dominant 'demand' factor behind the business cycle dynamics of the data has strong implications for structural economic models. Our analysis suggests a test for empirical models in terms of the nature of the behavior that shocks must exhibit in order to be considered as a plausible source of business cycles. Further, this test is completely independent of any economic interpretation of our findings and relies only on principal component space being a description of the data. 


\section{REFERENCES}

Adelman, I., and F. Adelman, 1959, “The Dynamic Properties of the Klein-Goldberger Model," Econometrica, , No. 4, pp. 596-625.

Andrle, M., 2012, “Cheers to Good Health of the US Phillips Curve: 1960-2012,” Techn. rep., International Monetary Fund.

Andrle, Michal, Jan Brůha, and Serhat Solmaz, 2016, "On the Sources of Business Cycles: Implications for DSGE Models," Czech National Bank Working Paper No. 3/2016.

Andrle, Michal, Jan Bruha, and Serhat Solmaz, 2013, "Inflation and Output Comovement in the Euro Area: Love at Second Sight?” IMF Working Papers 13/192, International Monetary Fund.

Brillinger, D.R., 1981, Time Series: Data Analysis and Theory (San Francisco: Holden-Day).

Burns, A.F., and W.C. Mitchell, 1946, Measuring Business Cycles (New York: NBER).

Cochrane, J., 1994, "Shocks," Carnegie-Rochester Conference Series on Public Policy, Vol. 41, pp. 295-364.

Forni, Mario, Marc Hallin, Marco Lippi, and Lucrezia Reichlin, 2000, “The Generalized Dynamic-Factor Model: Identification And Estimation," The Review of Economics and Statistics, Vol. 82, No. 4, pp. 540-554.

Justiniano, A., G.E. Primiceri, and A. Tambalotti, 2010, "Investment Shock and Business Cycles,” Journal of Monetary Economics, Vol. 57, No. 2, pp. 132-145.

Kindleberger, Ch. P., and R.Z. Aliber, 2005, Manias, Panics and Crashes, Fifth Ed. (New York: Palgrave MacMillan).

Koopman, L.H., 1974, The Spectral Analysis of Time Series (San Diego, CA: Academic Press).

Koopmans, T.C., 1957, "Measurement without Theory," Review of Economic Statistics, Vol. 29, No. August, pp. 161-172.

Kydland, F.E., and E.C. Prescott, 1990, "Business Cycles: Real Facts and a Monetary Myth," Federal Reserve Bank of Minneapolis Quarterly Review, Vol. Sping, pp. 3-18.

Meyer, Brent, and Saeed Zaman, 2013, "It's not just for inflation: The usefulness of the median CPI in BVAR forecasting," Working Paper 1303, Federal Reserve Bank of Cleveland, URL http://ideas.repec.org/p/fip/fedcwp/1303.html.

Pollock, D.S.G., 2013, "Cycles, Syllogisms and Semantics: Examining the Idea of Spurious Cycles," Journal of Time Series Econometrics, Vol. 6, No. 1, pp. 81-102. 
Sargent, T.J., and C.A. Sims, 1977, "Business cycle modeling without pretending to have too much a-priori economic theory," in New Methods in Business Cycle Research, ed. by C. Sims et al. (FRB of Minneapolis, Minneapolis).

Stock, James, and Marc W. Watson, 2002, "Macroeconomic forecasting using diffusion indexes," Journal of Business and Economic Statistics, Vol. 20, pp. 147-162.

Summers, L.H., 1986, "Some Skeptical Observations on real business cycle theory," Federal Reserve Bank of Minneapolis Quarterly Review, Vol. Fall, pp. 23-27.

Wu, C.F.J., 1986, "Jackknife, bootstrap and other resampling methods in regression analysis (with discussions)," Annals of Statistics, Vol. 14, pp. 1261-1350. 


\section{Appendix A. AdDitional GraphS}

Figure 8. Inflation Components - Decomposition
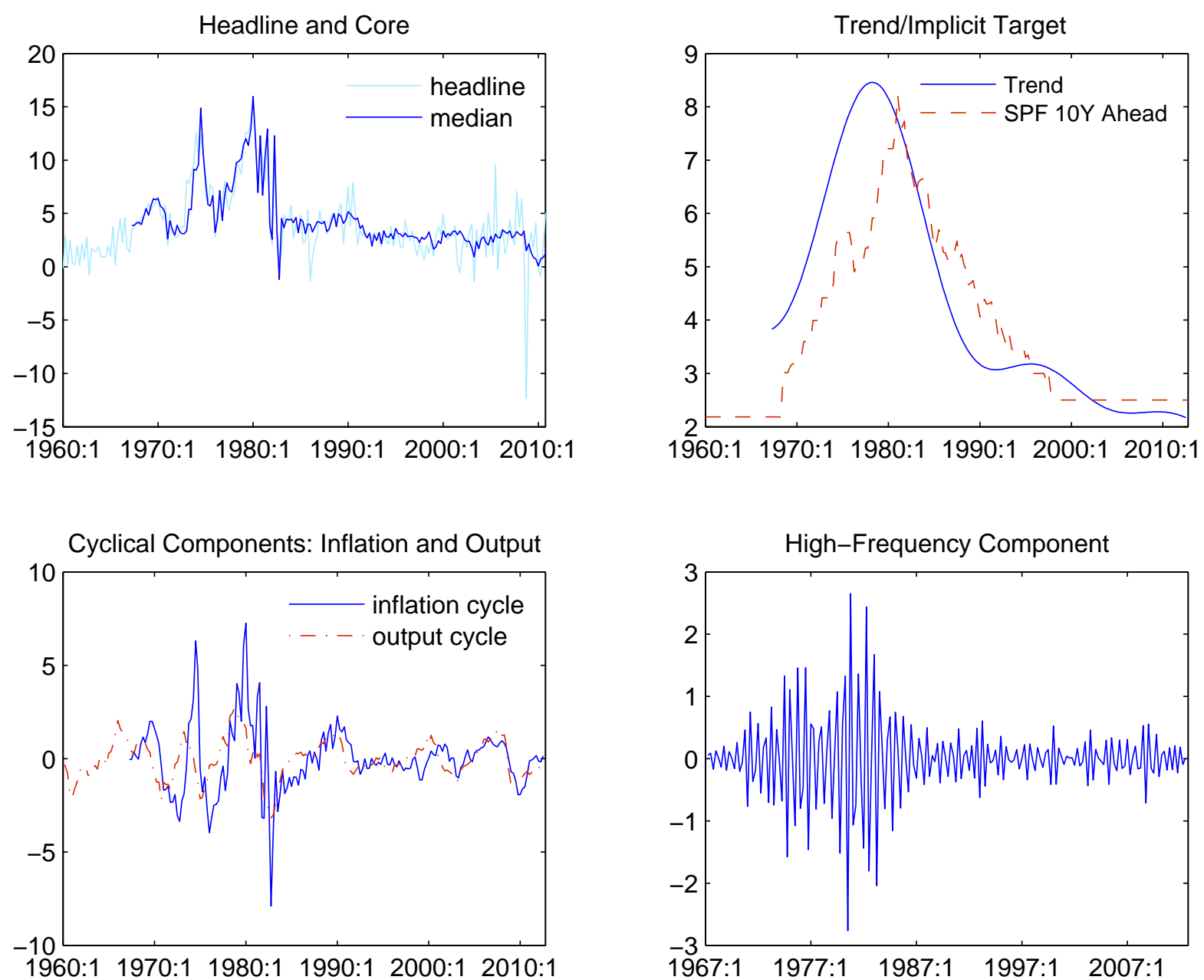

Source: own computations 
Figure 9. Cyclical components: data and fit with the DPCA (Christiano-Fitzgerald filter) - the U.S. (full sample)
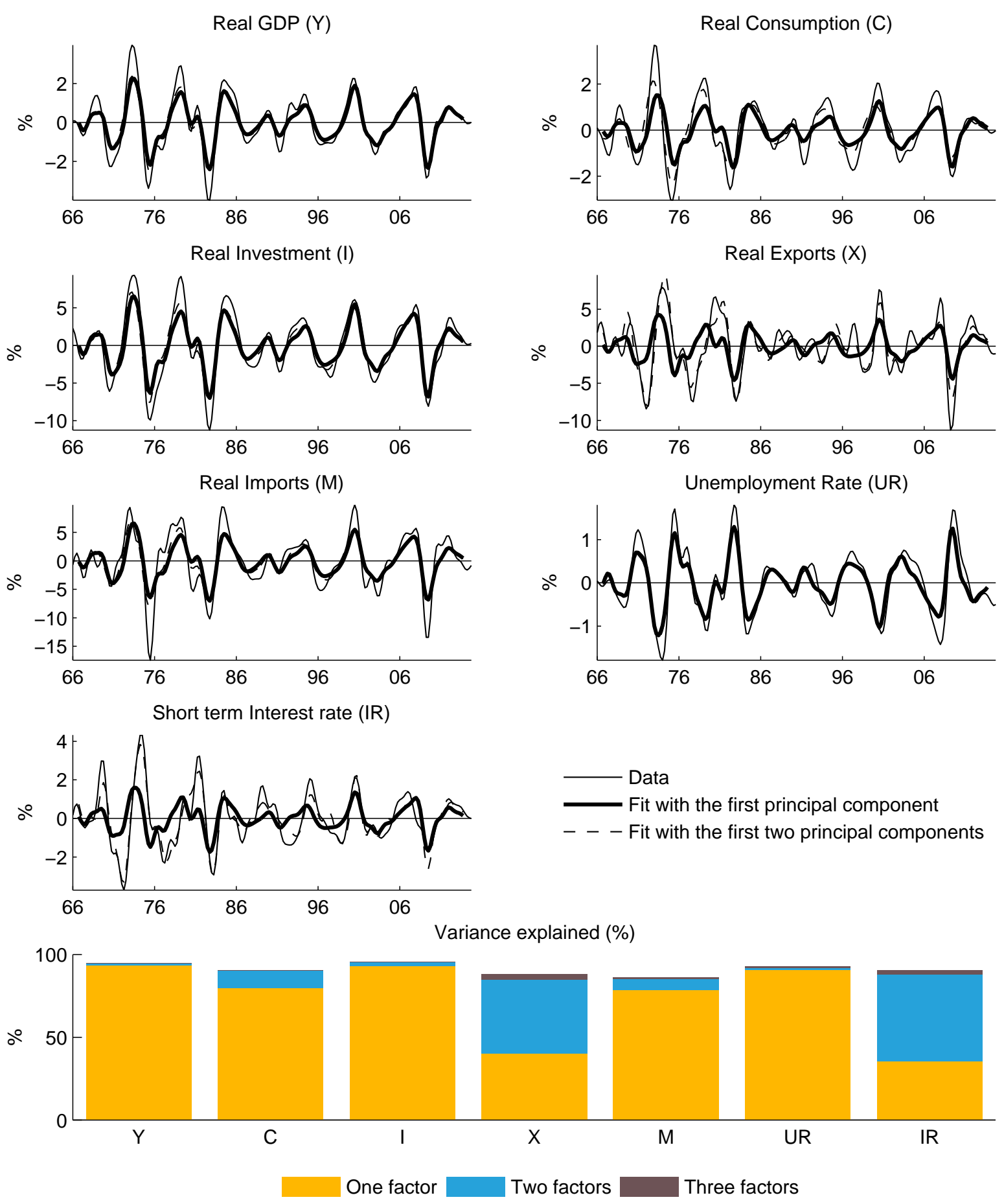
Figure 10. Cyclical components (Hodrick-Prescott filter): data and fit with the DPCA - the U.S. (1966Q2-2015Q4)
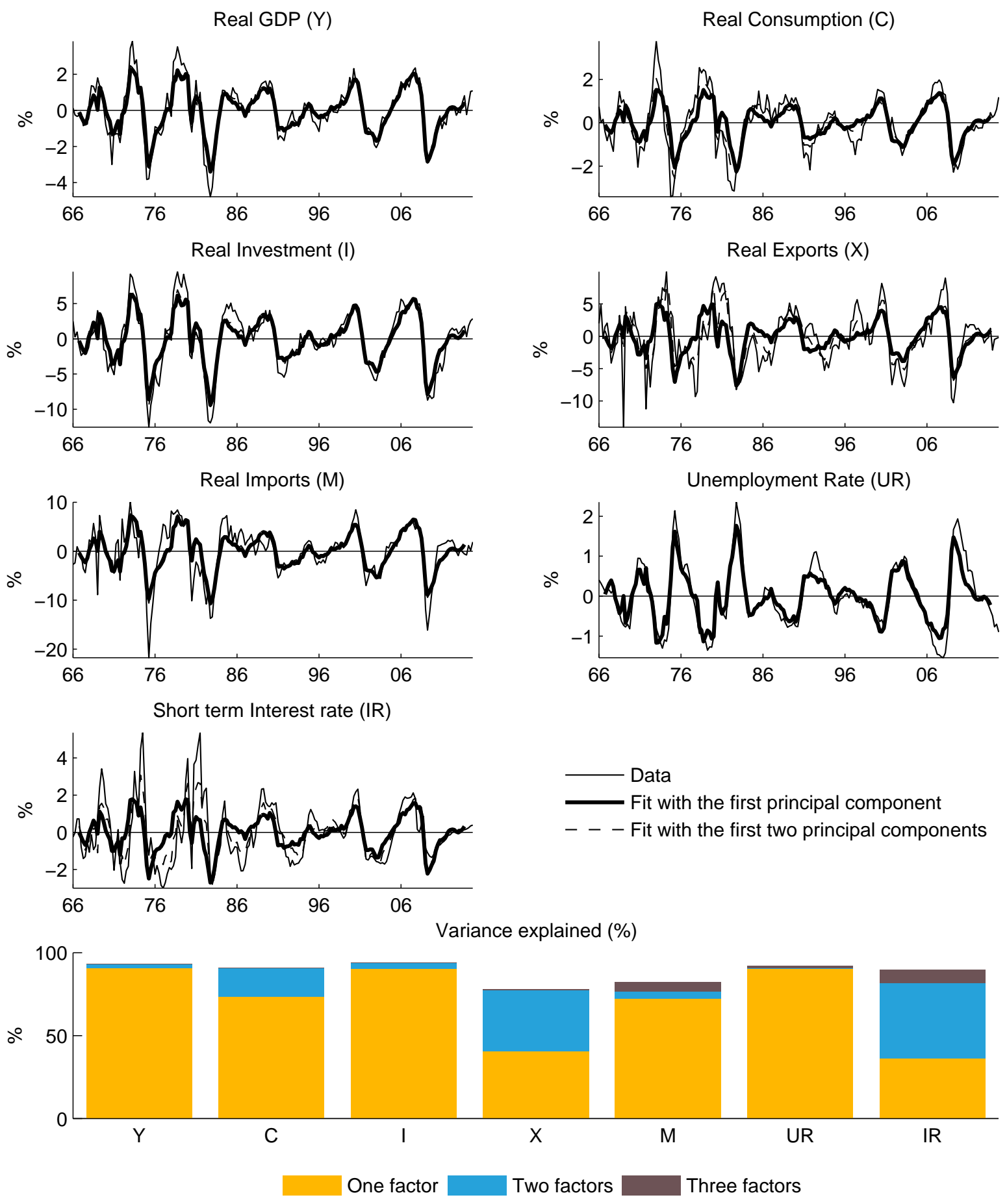
Figure 11. Spectral density of HP-filtered series: data and fit using the DPCA - the U.S.
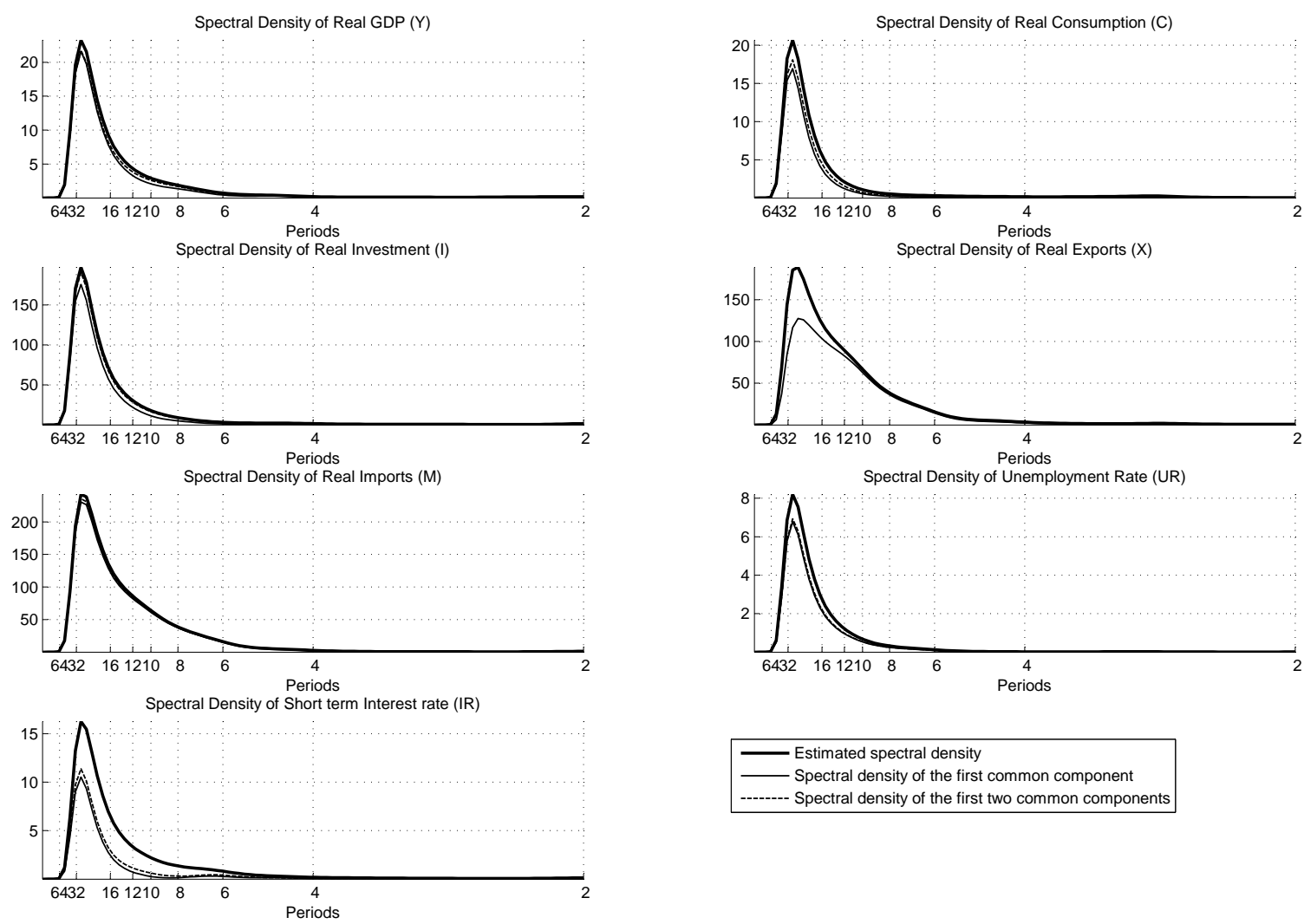
Figure 12. The DPCA in time domain for all variables together (HP cycles) - the U.S.
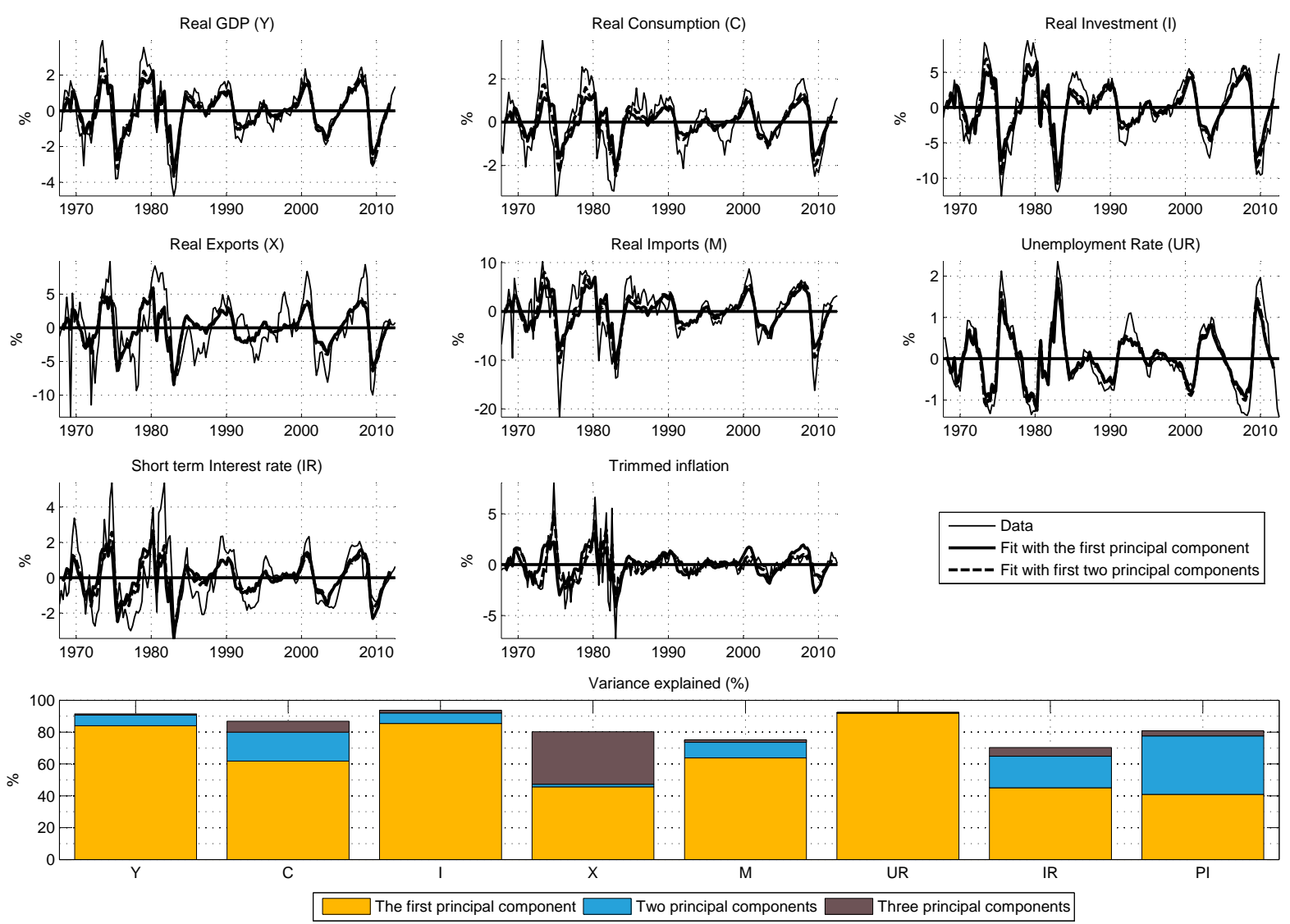
Figure 13. Cyclical components: data and fit with the DPCA (HP filter) - Japan
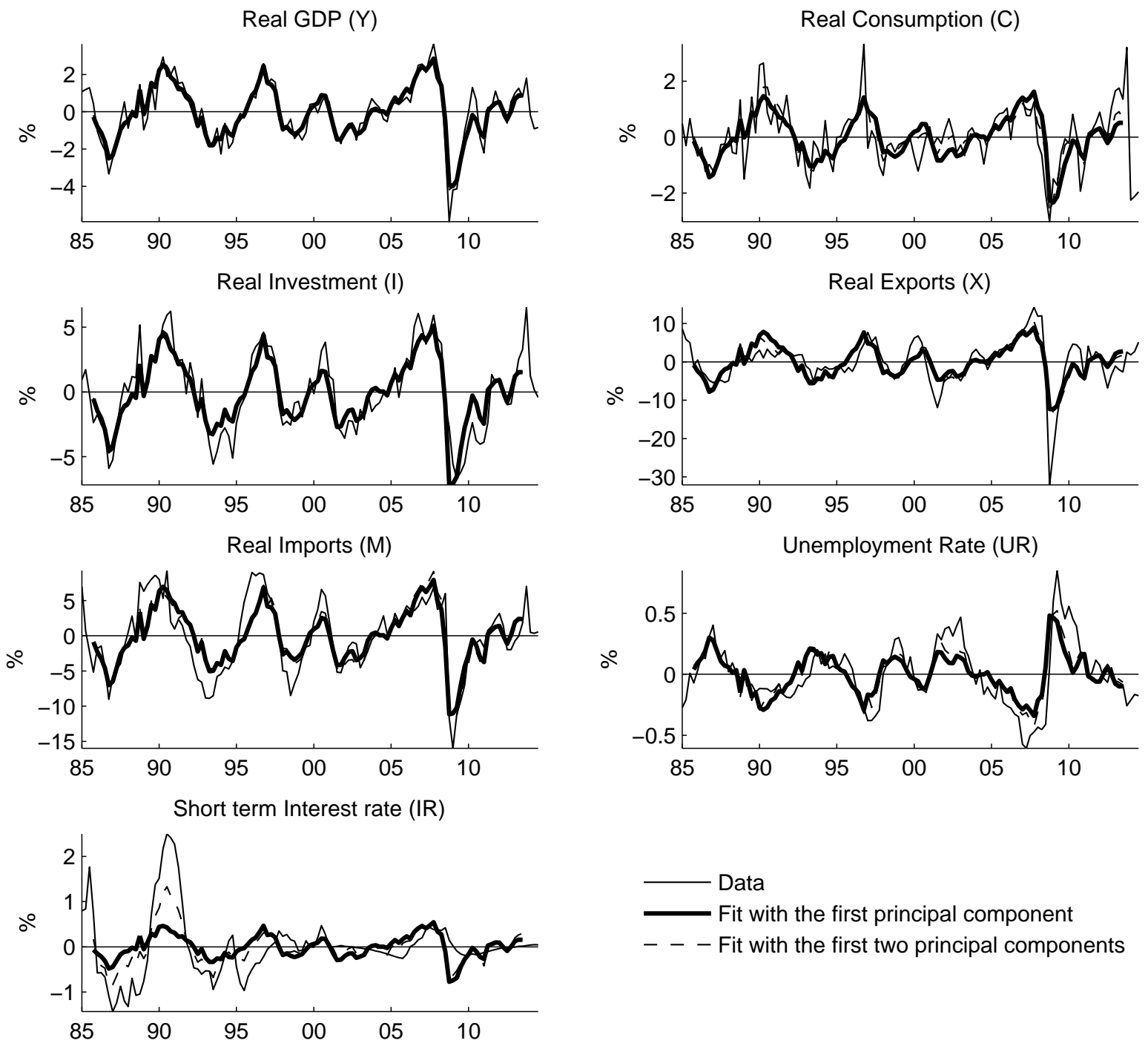

- Data

Fit with the first principal component

_ - - Fit with the first two principal components

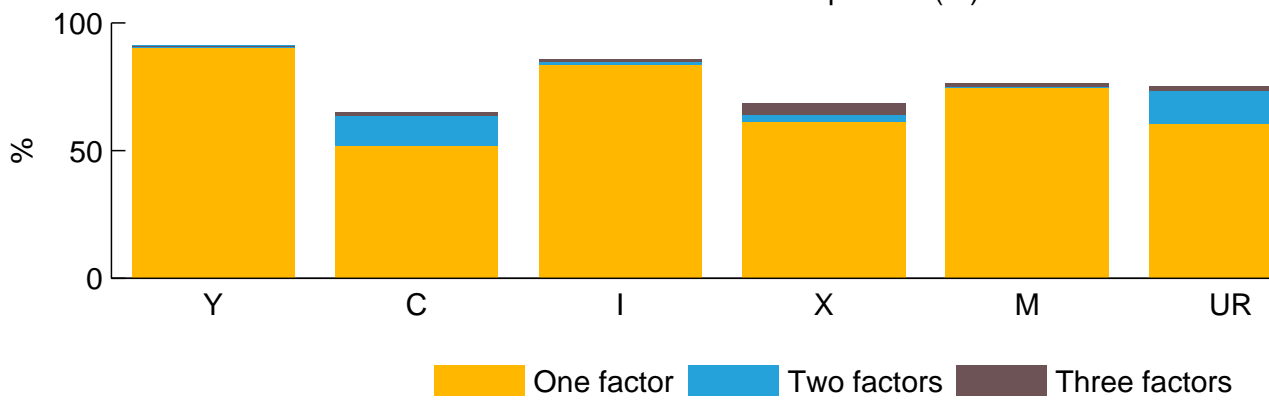


Figure 14. Cyclical components: data and fit with the DPCA (HP filter) - Germany
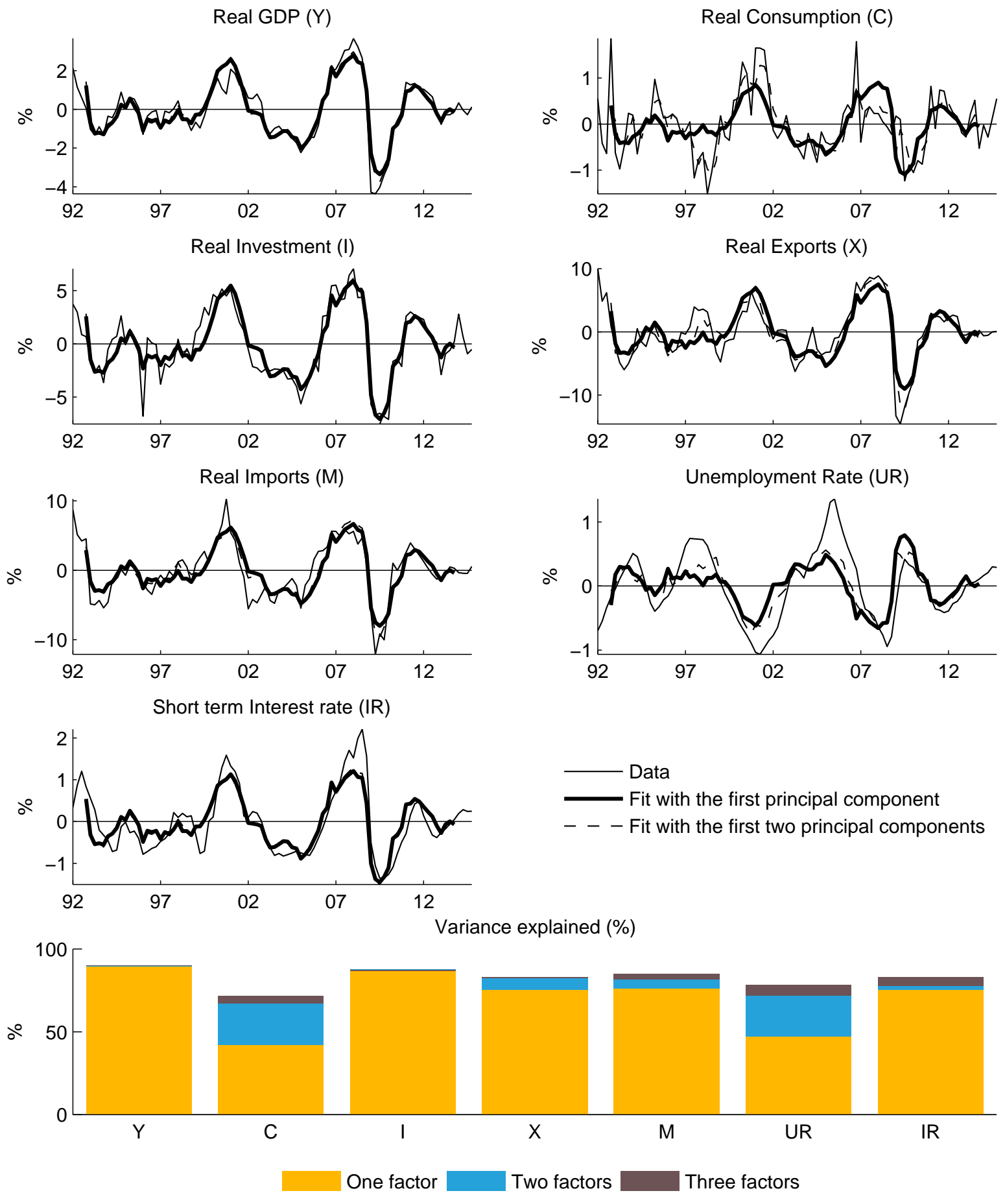
Figure 15. The boxplot summary statistics (the whole sample)
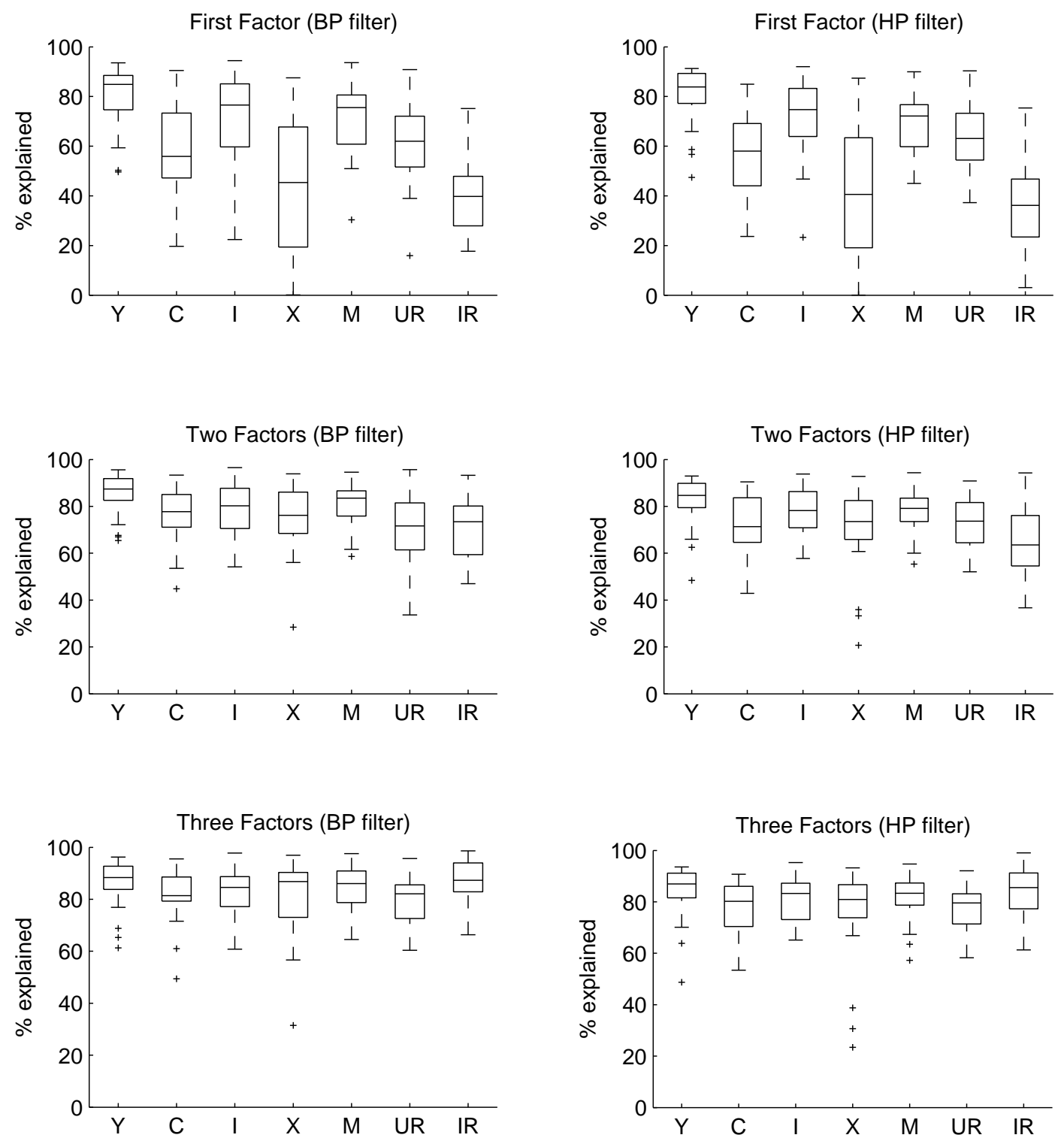
Figure 16. Growth Rates of Macroeconomic Data Consistent with Justiniano, Primiceri, and Tambalotti (2010)

Consumption vs. Investment Growth (q/q, ann.)

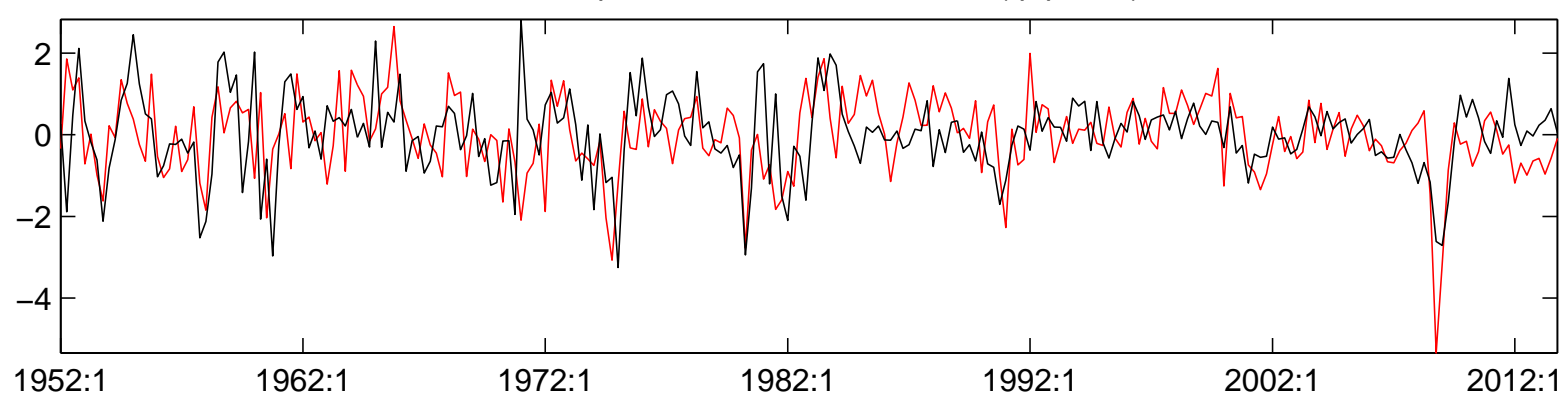

Output vs. Hours Worked Growth (q/q, ann.)

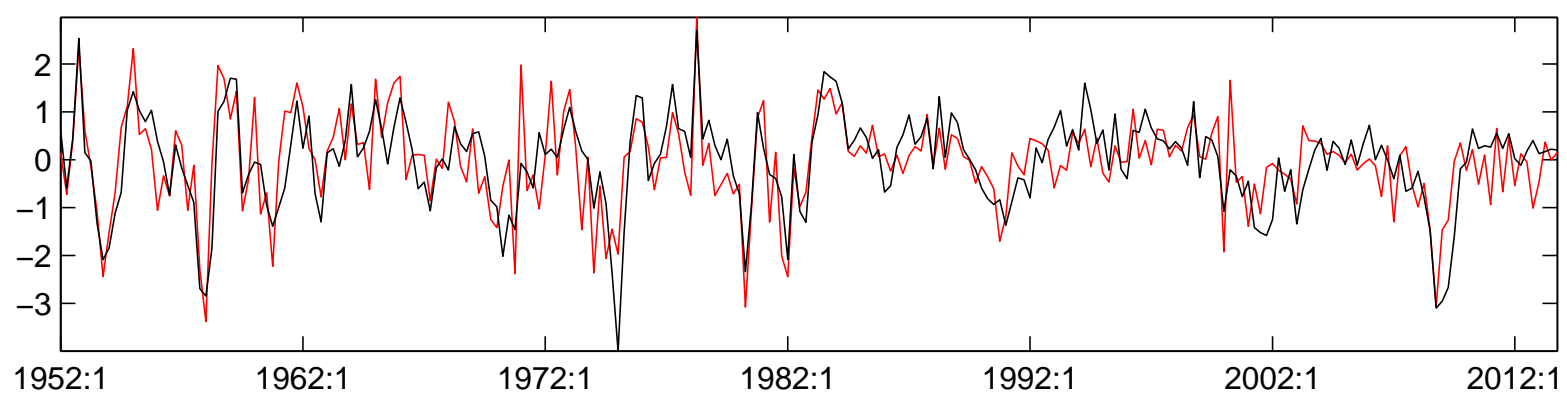

Output vs. Investment Growth (q/q, ann.)

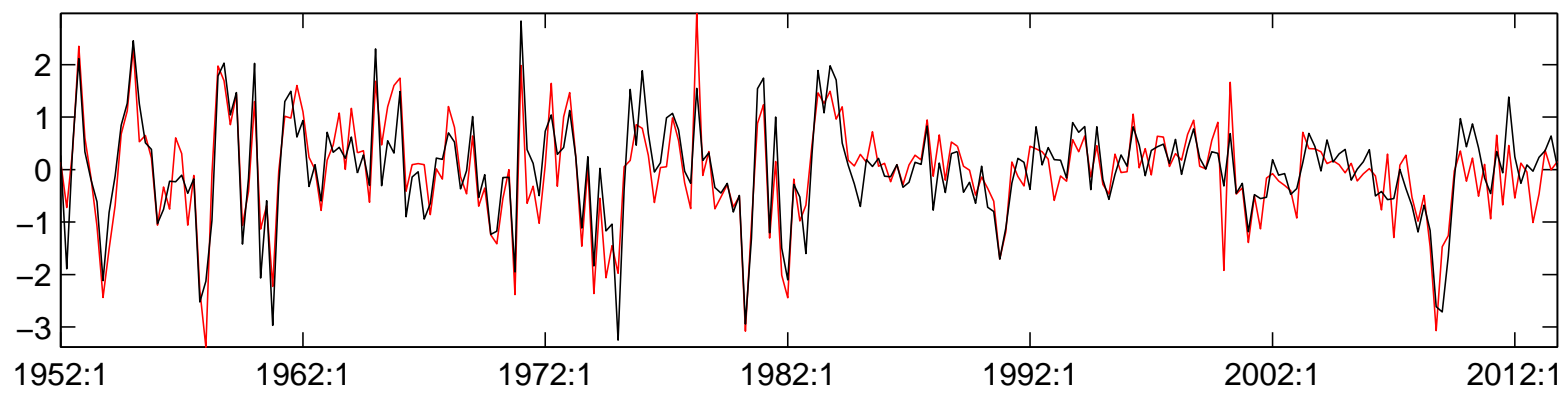

Consumption vs. Hours Worked (q/q, ann.)

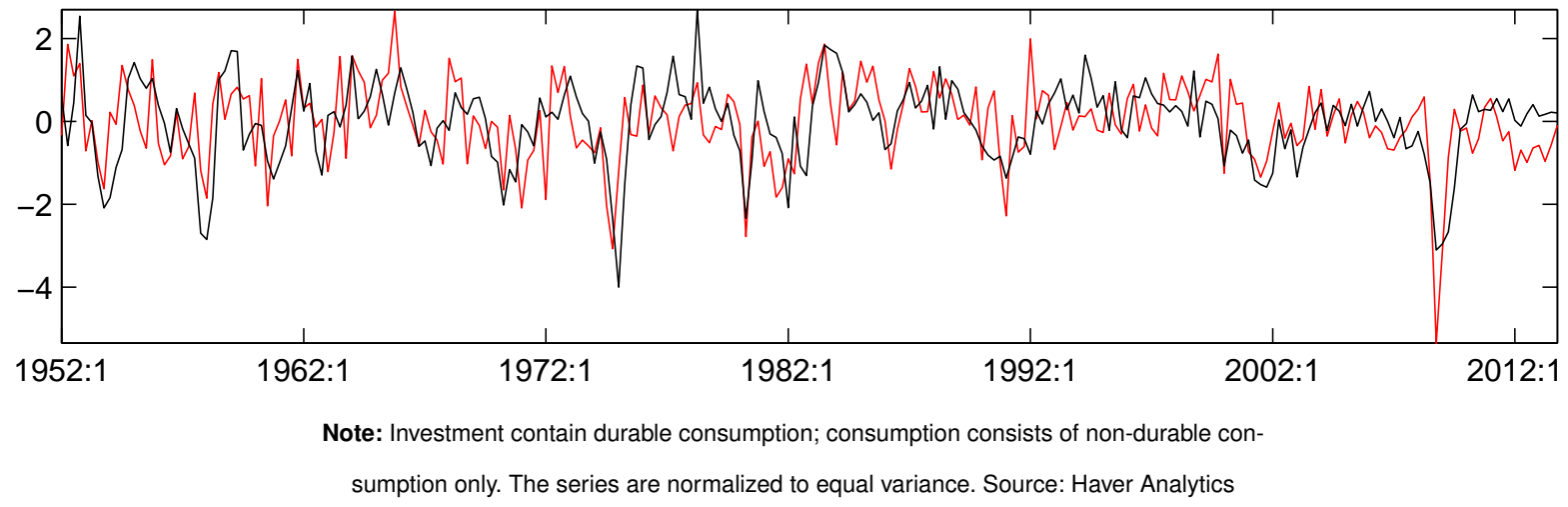


Figure 17. US Export Cycle - Actual and Trade-Weighted Foreign Demand

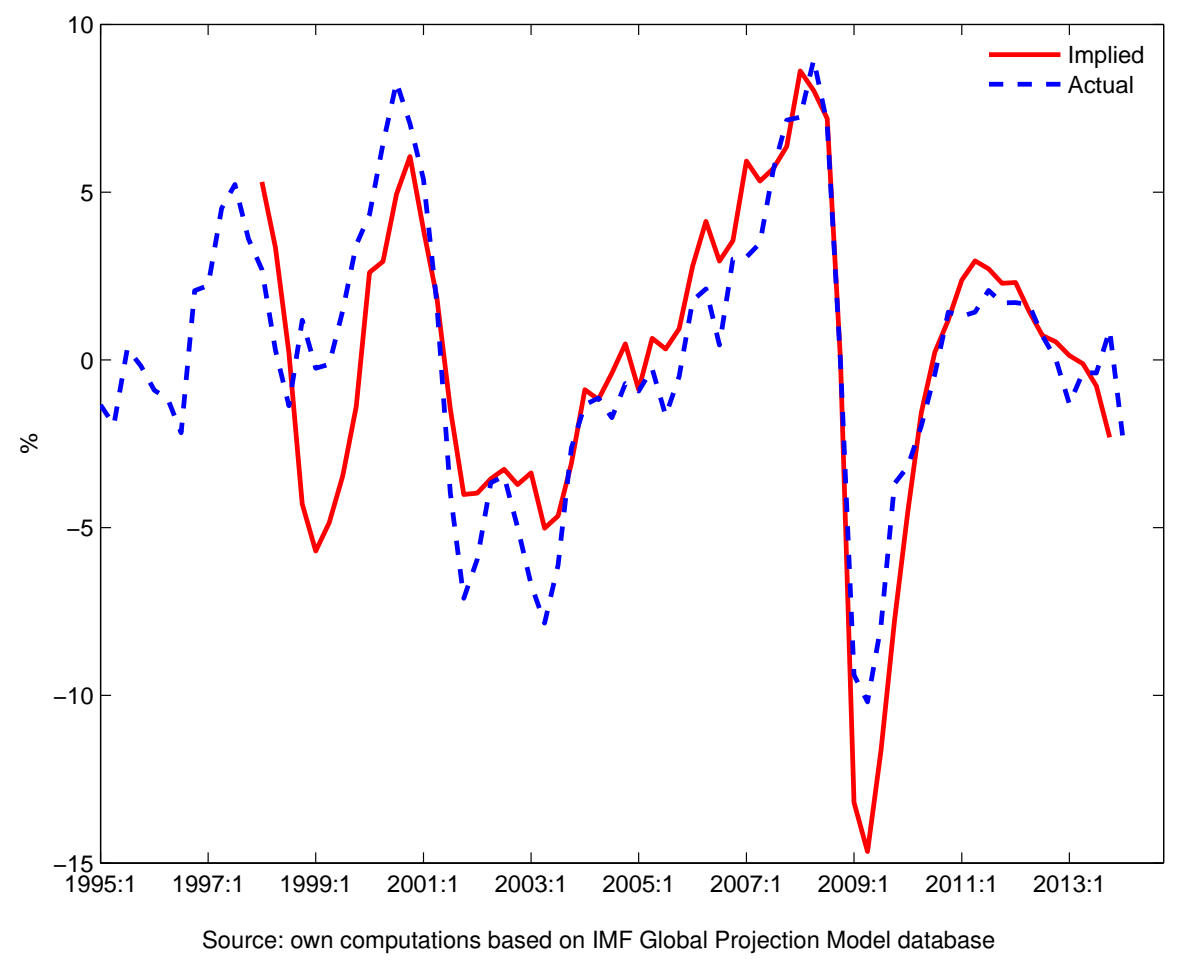




\section{APPENDix B. DAta Sources And SPECification}

Below the specification of the data is described. All computations were performed in Matlab by MathWorks. Data and codes for the paper are available upon request.

Trimmed-mean inflation for EU countries was computed using the data from the EUROSTAT as represented in the Haver Analytics database, Level 3. In the case of the United States the weighted median inflation is from FRB Cleveland. Trimmed-mean inflation for Australia was obtained from the Reserve Bank of Australia website. Ten-years-ahead inflation expectations obtained from the Survey of Professional Forecasters (SPF) by FRB of Philadelphia. The 'PTR' variable (proxy for inflation target) of FRB/US model has been kindly provided by Bob Tetlow.

Seasonal data adjustment provided by the source authority, otherwise default Bureau of Census X12/ARIMA algorithm was aplied in its default setting.

Table 1. OECD Data

\begin{tabular}{||l||l|l|}
\hline \hline Countries & \multicolumn{1}{|c|}{ Variables Collected per Country } & Data Source \\
\hline \hline Euro Area15 & Private final consumption expenditure, value, GDP expenditure approach & \\
Australia, Austria, & Private final consumption expenditure, volume & \\
Belgium, Canada, & Gross domestic product, value, market prices & \\
Finland, France, & Gross domestic product, volume, market prices & \\
Germany, Ireland, & Gross fixed capital formation, total, value & \\
Italy, Japan, & Gross fixed capital formation, total, volume & \\
Korea, Luxemburg, & Imports of goods and services, value, National Accounts basis & \\
Mexico, Netherland, & Imports of goods and services, volume, National Accounts basis & OECD Economic Outlook No. 94 \\
New Zealand, Norway, & Exports of goods and services, value, National Accounts basis \\
Poland, Portugal, & Exports of goods and services, volume, National Accounts basis & \\
Spain, Sweden, & Core inflation index & \\
Switzerland, United Kingdom , & Unemployment rate & \\
United States of America & Short-term interest rate & \\
\hline \hline
\end{tabular}




\section{Table 2. National Source Data}

\begin{tabular}{|c|c|}
\hline Czech Rep: GDP: Final Consumption Expenditure: Households (SWDA, Mil.CZK) & Czech Statistical Office \\
\hline Czech Rep: GDP: Final Consumption Exp: Households (SWDA, Mil.Chn.2005.CZK) & Czech Statistical Office \\
\hline Czech Republic: Gross Domestic Product (SWDA, Mil.CZK) & Czech Statistical Office \\
\hline Czech Republic: Gross Domestic Product (SWDA, Mil.Chn.2005.CZK) & Czech Statistical Office \\
\hline Czech Republic: GDP: Gross Fixed Capital Formation (SWDA, Mil.CZK) & Czech Statistical Office \\
\hline Czech Republic: GDP: Gross Fixed Capital Formation (SWDA, Mil.Chn.2005.CZK) & Czech Statistical Office \\
\hline Czech Republic: GDP: Imports of Goods and Services (SA, Mil.CZK) & Czech Statistical Office \\
\hline Czech Republic: GDP: Imports of Goods and Services (SA, Mil.Chn.2005.CZK) & Czech Statistical Office \\
\hline Czech Republic: GDP: Exports of Goods and Services (SA, Mil.CZK) & Czech Statistical Office \\
\hline Czech Republic: GDP: Exports of Goods and Services (SA, Mil.Chn.2005.CZK) & Czech Statistical Office \\
\hline Czech Republic: Unemployment Rate, \% of Labor Force (SA, \%) & Czech Statistical Office \\
\hline Czech Republic: PRIBOR: 3 Month (Avg, \%) & Czech National Bank \\
\hline Denmark: Private Consumption Expenditure (SA, Mil.Kroner) & Danmarks Statistik \\
\hline Denmark: Private Consumption Expenditure (SA, Mil.Chn.2005.Kroner) & Danmarks Statistik \\
\hline Denmark: Gross Domestic Product (SA, Mil.Kroner) & Danmarks Statistik \\
\hline Denmark: Gross Domestic Product (SA, Mil.Chn.2005.Kroner) & Danmarks Statistik \\
\hline Denmark: Gross Fixed Capital Formation (SA, Mil.Kroner) & Danmarks Statistik \\
\hline Denmark: Gross Fixed Capital Formation (SA, Mil.Chn.2005.Kroner) & Danmarks Statistik \\
\hline Denmark: GDP: Imports of Goods and Services (SA, Mil.Kroner) & Danmarks Statistik \\
\hline Denmark: GDP: Imports of Goods and Services (SA, Mil.Chn.2005.Kroner) & Danmarks Statistik \\
\hline Denmark: GDP: Exports of Goods and Services (SA, Mil.Kroner) & Danmarks Statistik \\
\hline Denmark: GDP: Exports of Goods and Services (SA, Mil.Chn.2005.Kroner) & Danmarks Statistik \\
\hline Denmark: Harmonized Unemployment Rate (SA, \%) & Statistical Office of the European Communities \\
\hline Denmark: Interbank Offered Rate: 3-months (AVG, \%) & Danmarks Nationalbank \\
\hline Greece: GDP: Private Consumption (NSA, Mil.Euros) & Hellenic Statistical Authority (ELSTAT) \\
\hline Greece: GDP: Private Consumption (NSA, Mil.Chained.2005.Euros) & Hellenic Statistical Authority (ELSTAT) \\
\hline Greece: Gross Domestic Product (NSA, Mil.Euros) & Hellenic Statistical Authority (ELSTAT) \\
\hline Greece: Gross Domestic Product (NSA, Mil.Chained.2005.Euros) & Hellenic Statistical Authority (ELSTAT) \\
\hline Greece: GDP: Gross Fixed Capital Formation (NSA, Mil.Euros) & Hellenic Statistical Authority (ELSTAT) \\
\hline Greece: GDP: Gross Fixed Capital Formation (NSA, Mil.Chained.2005.Euros) & Hellenic Statistical Authority (ELSTAT) \\
\hline Greece: GDP: Imports of Goods \& Services (NSA, Mil.Euros) & Hellenic Statistical Authority (ELSTAT) \\
\hline Greece: GDP: Imports of Goods \& Services (NSA, Mil.Chained.2005.Euros) & Hellenic Statistical Authority (ELSTAT) \\
\hline Greece: GDP: Exports of Goods \& Services (NSA, Mil.Euros) & Hellenic Statistical Authority (ELSTAT) \\
\hline Greece: GDP: Exports of Goods \& Services (NSA, Mil.Chained.2005.Euros) & Hellenic Statistical Authority (ELSTAT) \\
\hline Greece: Labor Force Survey: Unemployment Rate (SA, \%) & Hellenic Statistical Authority (ELSTAT) \\
\hline Hungary: Final Consumption Expenditure: Private (SA, Bil.Forints) & Central Statistical Office \\
\hline Hungary: GDP: Final Consumption Expenditure: Private (SWDA,Bil.Ch.2005.Forints) & Central Statistical Office \\
\hline Hungary: Gross Domestic Product (SA, Bil.Forints) & Central Statistical Office \\
\hline Hungary: Gross Domestic Product (SWDA, Bil.Ch.2005.Forints) & Central Statistical Office \\
\hline Hungary: Gross Fixed Capital Formation (SA, Bil.Forints) & Central Statistical Office \\
\hline Hungary: GDP: Gross Fixed Capital Formation (SWDA,Bil.Ch.2005.Forints) & Central Statistical Office \\
\hline Hungary: Imports of Goods \& Services (SA, Bil.Forints) & Central Statistical Office \\
\hline Hungary: GDP: Imports of Goods \& Services (SWDA,Bil.Ch.2005.Forints) & Central Statistical Office \\
\hline Hungary: Exports of Goods \& Services (SA, Bil.Forints) & Central Statistical Office \\
\hline Hungary: GDP: Exports of Goods \& Services (SWDA,Bil.Ch.2005.Forints) & Central Statistical Office \\
\hline Hungary: Unemployment Rate (SA, \%) & Central Statistical Office \\
\hline Hungary: Yield on 3-Month Government Debt Securities (EOP, \% per annum) & National Bank of Hungary \\
\hline
\end{tabular}




\section{Table 3. National Source Data}

\begin{tabular}{|c|c|}
\hline Slovakia: GDP: Final Consumption of Households (SA, Mil.EUR) & Statistical Office of the Slovak Republic \\
\hline Slovakia: GDP: Final Consumption of Households (SA, Mil.Chn.2005.EUR) & Statistical Office of the Slovak Republic \\
\hline Slovakia: Gross Domestic Product (SA, Mil.EUR) & Statistical Office of the Slovak Republic \\
\hline Slovakia: Gross Domestic Product (SA, Mil.Chn.2005.EUR) & Statistical Office of the Slovak Republic \\
\hline Slovakia: GDP: Gross Fixed Capital Formation (SA, Mil.EUR) & Statistical Office of the Slovak Republic \\
\hline Slovakia: GDP: Gross Fixed Capital Formation (SA, Mil.Chn.2005.EUR) & Statistical Office of the Slovak Republic \\
\hline Slovakia: GDP: Import of Goods and Services (SA, Mil.EUR) & Statistical Office of the Slovak Republic \\
\hline Slovakia: GDP: Import of Goods and Services (SA, Mil.Chn.2005.EUR) & Statistical Office of the Slovak Republic \\
\hline Slovakia: GDP: Export of Goods and Services (SA, Mil.EUR) & Statistical Office of the Slovak Republic \\
\hline Slovakia: GDP: Export of Goods and Services (SA, Mil.Chn.2005.EUR) & Statistical Office of the Slovak Republic \\
\hline Slovakia: Unemployment Rate [Registered] (SA, \%) & Central Office of Labour, Social Affairs and Family \\
\hline Slovakia: New Household Deposits: Redeemable at Notice: Up to 3 Months (\%) & National Bank of Slovakia \\
\hline Slovenia: GDP: Final Consumption: Households (SWDA, Mil.EUR) & Statistical Office of the Republic of Slovenia \\
\hline Slovenia: GDP: Final Consumption: Households (SWDA, Mil.Chn.2000.EUR) & Statistical Office of the Republic of Slovenia \\
\hline Slovenia: Gross Domestic Product (SWDA, Mil.EUR) & Statistical Office of the Republic of Slovenia \\
\hline Slovenia: Gross Domestic Product (SWDA, Mil.Chn.2000.EUR) & Statistical Office of the Rep of Slovenia \\
\hline Slovenia: GDP: Gross Fixed Capital Formation (SWDA, Mil.EUR) & Statistical Office of the Republic of Slovenia \\
\hline Slovenia: GDP: Gross Fixed Capital Formation (SWDA, Mil.Chn.2000.EUR) & Statistical Office of the Republic of Slovenia \\
\hline Slovenia: GDP: Imports of Goods and Services (SWDA, Mil.EUR) & Statistical Office of the Republic of Slovenia \\
\hline Slovenia: GDP: Imports of Goods and Services (SWDA, Mil.Chn.2000.EUR) & Statistical Office of the Republic of Slovenia \\
\hline Slovenia: GDP: Exports of Goods and Services (SWDA, Mil.EUR) & Statistical Office of the Republic of Slovenia \\
\hline Slovenia: GDP: Exports of Goods and Services (SWDA, Mil.Chn.2000.EUR) & Statistical Office of the Republic of Slovenia \\
\hline Slovenia: Unemployment Rate (\%) & International Monetary Fund / IFS \\
\hline Slovenia: Money Market Rate (\% per annum) & International Monetary Fund / IFS \\
\hline Turkey: Res/Nonresident HHs Final Consump Exp on Economic Territory(SA,Thous.TL) & Turkish Statistical Institute \\
\hline Turkey: Res/Nonres HHs Final Consump Exp on Economic Territory (SA, Thous.98.TL) & Turkish Statistical Institute \\
\hline Turkey: Gross Domestic Product (SA, Thous. TL) & Turkish Statistical Institute \\
\hline Turkey: Gross Domestic Product (SA, Thous.98.TL) & Turkish Statistical Institute \\
\hline Turkey: Gross Fixed Capital Formation (SA, Thous.TL) & Turkish Statistical Institute \\
\hline Turkey: Gross Fixed Capital Formation (SA, Thous.98.TL) & Turkish Statistical Institute \\
\hline Turkey: Exports of Goods \& Services (SA, Thous.TL) & Turkish Statistical Institute \\
\hline Turkey: Exports of Goods \& Services (SA, Thous.98.TL) & Turkish Statistical Institute \\
\hline Turkey: Imports of Goods \& Services (SA, Thous.TL) & Turkish Statistical Institute \\
\hline Turkey: Imports of Goods \& Services (SA, Thous.98.TL) & Turkish Statistical Institute \\
\hline Turkey: Unemployment Rate (SA, \% of Labor Force) & Turkish Statistical Institute \\
\hline Turkey: Weighted Average Interest Rates for TL Deposits: Up to 3 Months(\% p.a.) & Central Bank of the Republic of Turkey \\
\hline
\end{tabular}

